\title{
Radiolysis of $\mathrm{H}_{2} \mathrm{O}: \mathrm{CO}_{2}$ ices by heavy energetic cosmic ray analogs
}

\author{
S. Pilling ${ }^{1}$, E. Seperuelo Duarte ${ }^{2}$, A. Domaracka ${ }^{3}$, H. Rothard ${ }^{3}$, P. Boduch ${ }^{3}$, and E. F. da Silveira ${ }^{4}$ \\ 1 IP\&D/UNIVAP, Av. Shishima Hifumi, 2911, São Jose dos Campos, SP, Brazil \\ e-mail: sergiopilling@pq.cnpq.br \\ 2 Grupo de Física e Astronomia, CEFET/Química de Nilópolis, Rua Lúcio Tavares, 1052, CEP 2653-060, Nilópolis, Brazil \\ 3 Centre de Recherche sur les Ions, les Matériaux et la Photonique (CEA/CNRS/ENSICAEN/Université de Caen-Basse Normandie), \\ CIMAP - CIRIL - GANIL, Boulevard Henri Becquerel, BP 5133, 14070 Caen Cedex 05, France \\ 4 Departamento de Física, Pontifícia Universidade Católica do Rio de Janeiro (PUC-Rio), Rua Marquês de São Vicente 225, \\ CEP 22453-900, Rio de Janeiro, Brazil
}

Received 1 June 2010 / Accepted 3 August 2010

\begin{abstract}
An experimental study of the interaction of heavy, highly charged, and energetic ions $\left(52 \mathrm{MeV}^{58} \mathrm{Ni}^{13+}\right)$ with pure $\mathrm{H}_{2} \mathrm{O}$, pure $\mathrm{CO}_{2}$ and mixed $\mathrm{H}_{2} \mathrm{O}: \mathrm{CO}_{2}$ astrophysical ice analogs is presented. This analysis aims to simulate the chemical and the physicochemical interactions induced by heavy cosmic rays inside dense and cold astrophysical environments, such as molecular clouds or protostellar clouds. The measurements were performed at the heavy ion accelerator GANIL (Grand Accélérateur National d'Ions Lourds in Caen, France). The gas samples were deposited onto a CsI substrate at $13 \mathrm{~K}$. In-situ analysis was performed by a Fourier transform infrared (FTIR) spectrometer at different fluences. Radiolysis yields of the produced species were quantified. The dissociation cross sections of pure $\mathrm{H}_{2} \mathrm{O}$ and $\mathrm{CO}_{2}$ ices are 1.1 and $1.9 \times 10^{-13} \mathrm{~cm}^{2}$, respectively. For mixed $\mathrm{H}_{2} \mathrm{O}: \mathrm{CO}_{2}(10: 1)$, the dissociation cross sections of both species are about $1 \times 10^{-13} \mathrm{~cm}^{2}$. The measured sputtering yield of pure $\mathrm{CO}_{2}$ ice is $2.2 \times 10^{4} \mathrm{molec}^{-1}$. After a fluence of $2-3 \times$ $10^{12}$ ions $\mathrm{cm}^{-2}$, the $\mathrm{CO}_{2} / \mathrm{CO}$ ratio becomes roughly constant $(\sim 0.1)$, independent of the initial $\mathrm{CO}_{2} / \mathrm{H}_{2} \mathrm{O}$ ratio. A similar behavior is observed for the $\mathrm{H}_{2} \mathrm{O}_{2} / \mathrm{H}_{2} \mathrm{O}$ ratio, which stabilizes at 0.01 , independent of the initial $\mathrm{H}_{2} \mathrm{O}$ column density or relative abundance.
\end{abstract}

Key words. astrochemistry - molecular data - solar wind - cosmic rays - ISM: molecules - planets and satellites: composition

\section{Introduction}

$\mathrm{H}_{2} \mathrm{O}$ and $\mathrm{CO}_{2}$ are most abundant constituents of icy grain mantles in the interstellar medium (Whittet et al. 1996; Ehrenfreund \& Charnley 2000). Following Gerakines et al. (1999), a significant fraction of interstellar solid $\mathrm{CO}_{2}$ exists in mixtures dominated by $\mathrm{H}_{2} \mathrm{O}$ in both quiescent cloud and protostellar regions. In those regions the relative abundance of $\mathrm{CO}_{2}$ with respect to $\mathrm{H}_{2} \mathrm{O}$ ranges from $4 \%$ to $25 \%$.

Inside the solar system the presence of $\mathrm{H}_{2} \mathrm{O}$ and $\mathrm{CO}_{2}$ ices is also ubiquitous. For example, $\mathrm{CO}_{2}$ is widely detected in cometary ices. Its abundance, relative to $\mathrm{H}_{2} \mathrm{O}$, is about $6-7 \%$ in the comets Hale-Bopp (Crovisier et al. 1997; Crovisier 1998) and Hyakutake (Bockelée-Morvan 1997). The $\mathrm{H}_{2} \mathrm{O}$ and $\mathrm{CO}_{2}$ ice features have been observed also in the IR spectra of the icy Galilean satellites Europa, Ganymede, Callisto (Carlson et al. 1999; McCord et al. 1998), Triton - the largest moon of Neptune (Quirico et al. 1999) - and on the surface of Mars (Herr \& Pimentel 1969; Larson \& Fink 1972).

Deep inside dense molecular clouds and protostellar disks, as well as on the surfaces of solar system bodies surrounded by thick atmospheres, the frozen compounds are protected from stellar energetic UV photons. However, X-rays and energetic cosmic rays can penetrate deeper and trigger molecular dissociation, chemical reactions, and evaporation processes. For solar system ices without significant atmospheres, such as Europa, Enceladus, and Oort cloud comets, the material protection to $\mathrm{UV}$ photons is supplied by the upper layers (tens of $\mathrm{nm}$ ) of ice, and only the energetic particles reach the inner layers (e.g., $52 \mathrm{MeV}$ Ni penetrate roughly $20 \mu \mathrm{m}$ in pure water ice). These ices are directly exposed to stellar photons, cosmic rays, solar wind ( $\sim 1 \mathrm{keV} / \mathrm{amu}$ ionized particles), and energetic solar particles and/or planetary magnetosphere particles.

Laboratory studies and astronomical observations indicate that photolysis and radiolysis of such ices can create simple molecules, such as $\mathrm{CO}, \mathrm{CO}_{3}, \mathrm{O}_{3}, \mathrm{H}_{2} \mathrm{CO}_{3}$, and $\mathrm{H}_{2} \mathrm{O}_{2}$, and other more complex organic compounds such as formic acid, formaldehyde, methanol, etc. (e.g. Gerakines et al. 2000; Moore \& Hudson 2000; Brucato et al. 1997; Wu et al. 2003). By comparing laboratory data (production rates, formation cross section, and half-lives for these compounds) with astronomical observation, we will better understand the physicochemical processes occurring in the astronomical sources.

In this work, we present infrared measurements of two different mixtures of $\mathrm{H}_{2} \mathrm{O}: \mathrm{CO}_{2}$ ices, as well as of pure water and $\mathrm{CO}_{2}$ ices, irradiated by $52 \mathrm{MeV}{ }^{58} \mathrm{Ni}^{13+}$. In Sect. 2, the experimental setup is briefly described. The infrared spectra of frozen sample measured as a function of ion fluences are the subject of Sect. 3. Section 4 has a discussion of the dissociation cross sections and other radiolysis-induced effects, as well as of the formation of new species on ices. Astrophysical implication is discussed in Sect. 5. Final remarks and conclusions are given in Sect. 6.

\section{Experimental}

To simulate the effects of heavy and highly ionized cosmic rays on astrophysical cold surfaces, we used the facilities at the heavy 
ion accelerator GANIL (Grand Accélérateur National d'Ions Lourds, Caen, France). The gas samples (purity superior to 99\%) were deposited onto a CsI substrate at $13 \mathrm{~K}$ through a facing gas inlet. The sample-cryostat system can be rotated $180^{\circ}$ and fixed at three different positions to allow i) gas deposition; ii) FTIR measurement; and iii) perpendicular ion irradiation.

${ }^{58} \mathrm{Ni}^{13+}$ ion projectiles with energies of $52 \mathrm{MeV}$ impinge perpendicularly onto both $\mathrm{H}_{2} \mathrm{O}: \mathrm{CO}_{2}$ ice (1:1), $\mathrm{H}_{2} \mathrm{O}: \mathrm{CO}_{2}$ ice (10:1) and onto pure $\mathrm{H}_{2} \mathrm{O}$ and $\mathrm{CO}_{2}$ ices. The target ionizing effects of $\mathrm{Ni}$ and Fe projectiles, at the same velocity, are almost identical since they almost have the same atomic number (Seperuelo Duarte et al. 2010). The incoming charge state 13+ corresponds approximately to the equilibrium charge state after several collisions of $52 \mathrm{MeV} \mathrm{Ni}$ atoms (independent of the initial charge state) with matter (e.g. Nastasi et al. 1996).

In-situ analysis was performed by the Nicolet FTIR spectrometer (Magna 550) from 4000 to $600 \mathrm{~cm}^{-1}$ with a resolution of $1 \mathrm{~cm}^{-1}$. The spectra were collected at different fluences up to $2 \times 10^{13}$ ions $\mathrm{cm}^{-2}$. The Ni ion flux was $2 \times 10^{9} \mathrm{~cm}^{-2} \mathrm{~s}^{-1}$. During the experiment the chamber pressure was below $2 \times 10^{-8}$ mbar owing to the cryopumping by the thermal shield. More details are given elsewhere (Seperuelo Duarte et al. 2009; Pilling et al. 2010).

Assuming an average density for the pure water ice and water-rich ice samples of $1 \mathrm{~g} / \mathrm{cm}^{3}$ and $1.8 \mathrm{~g} / \mathrm{cm}^{3}$ for the pure $\mathrm{CO}_{2}$ ice, the thickness, and the deposition rate are determined by using the initial molecular column density of the samples. For $\mathrm{H}_{2} \mathrm{O}: \mathrm{CO}_{2}(1: 1)$ and $\mathrm{H}_{2} \mathrm{O}: \mathrm{CO}_{2}(10: 1)$, the sample thicknesses were 0.6 and $0.4 \mu \mathrm{m}$. The deposition rates were roughly 7 and $3 \mu \mathrm{m} / \mathrm{h}$, respectively. For pure $\mathrm{H}_{2} \mathrm{O}$ ice and pure $\mathrm{CO}_{2}$ ice, the thicknesses were about 0.5 and $0.4 \mu \mathrm{m}$, and the deposition rates were 4 and $3 \mu \mathrm{m} / \mathrm{h}$, respectively. The penetration depth of $52 \mathrm{MeV} \mathrm{Ni}$ ions is much greater than ice thicknesses, therefore the ions pass though the target with approximately the same velocity (constant cross sections).

The molecular column density of a sample was determined from the relation between optical depth $\tau_{v}=\ln \left(I_{0} / I\right)$ and the band strength, $A\left(\mathrm{~cm} \mathrm{molec}^{-1}\right)$, of the respective sample vibrational mode (see d'Hendecourt \& Allamandola 1986). In this expression, $I$ and $I_{0}$ are the intensity of light at a specific frequency before and after passing through a sample, respectively. Since the absorbance measured by the FTIR spectrometer is $A b s_{v}=\log \left(I_{0} / I\right)$, the molecular column density of ice samples is given by

$N=\frac{1}{A} \int \tau_{\nu} \mathrm{d} v=\frac{2.3}{A} \int A b s_{\nu} \mathrm{d} v \quad\left[\right.$ molec $\left.\mathrm{cm}^{-2}\right]$,

where $A b s_{v}=\ln \left(I_{0} / I\right) / \ln (10)=\tau_{v} / 2.3$.

The vibrational band positions and their infrared absorption coefficients (band strengths) used in this work are given in Table 1.

\section{Results}

Figure 1a presents the infrared spectra of $\mathrm{H}_{2} \mathrm{O}: \mathrm{CO}_{2}$ ice $(1: 1)$ at $13 \mathrm{~K}$, before (top trace) and after different irradiation fluences. Each spectrum has been shifted for clarity. The narrow peak at $2342 \mathrm{~cm}^{-1}$ is the $\mathrm{CO}_{2}$ stretching mode $\left(v_{3}\right)$. The broad structures around 3300 and $800 \mathrm{~cm}^{-1}$ correspond to the vibration modes of water, $v_{1}$ and $v_{L}$, respectively. The band at $1600 \mathrm{~cm}^{-1}$ is due to the water $v_{2}$ vibration mode. The presence of the $\mathrm{OH}$ dangling band at about $3650 \mathrm{~cm}^{-1}$ is also observed in the figure indicating a high porosity (Palumbo et al. 2006). The inset figure shows the
Table 1. Infrared absorption coefficients (band strengths) used in the column density calculations for the observed molecules.

\begin{tabular}{lllll}
\hline \hline $\begin{array}{l}\text { Frequency } \\
\left(\mathrm{cm}^{-1}\right)\end{array}$ & $\begin{array}{l}\text { Wavelength Assignment } \\
(\mu \mathrm{m})\end{array}$ & \multicolumn{2}{l}{$\begin{array}{l}\text { Band strength }(A) \\
\left.(\mathrm{cm} \mathrm{molec})^{-1}\right)\end{array}$} & Ref. \\
\hline 2342 & 4.27 & $\mathrm{CO}_{2}\left(v_{3}\right)$ & $7.6 \times 10^{-17}$ & {$[1]$} \\
3250 & 3.07 & $\mathrm{H}_{2} \mathrm{O}\left(v_{1}\right)$ & $2.0 \times 10^{-16}$ & {$[1]$} \\
$\sim 2850$ & $\sim 3.5$ & $\mathrm{H}_{2} \mathrm{O}_{2}\left(v_{2}+v_{6}\right)$ & $5.7 \times 10^{-17}$ & {$[3]$} \\
2139 & 4.67 & $\mathrm{CO}\left(v_{1}\right)$ & $1.1 \times 10^{-17}$ & {$[2]$} \\
2044 & 4.89 & $\mathrm{CO}_{3}\left(v_{3}\right)$ & $8.9 \times 10^{-17}$ & {$[4]$} \\
1307 & 7.65 & $\mathrm{H}_{2} \mathrm{CO}_{3}(\mathrm{C}-\mathrm{OH}$ bend $)$ & $1.0 \times 10^{-16}$ & {$[5]$} \\
$\sim 1040$ & $\sim 9.6$ & $\mathrm{O}_{3}\left(v_{3}\right)$ & $1.4 \times 10^{-17}$ & {$[6]$} \\
\hline
\end{tabular}

References. [1] Gerakines et al. (1995); [2] Gibb et al. (2000); [3] Loeffler et al. (2006); [4] Bennett et al. (2004); [5] Gerakines et al. (2000); [6] Smith et al. (1985).
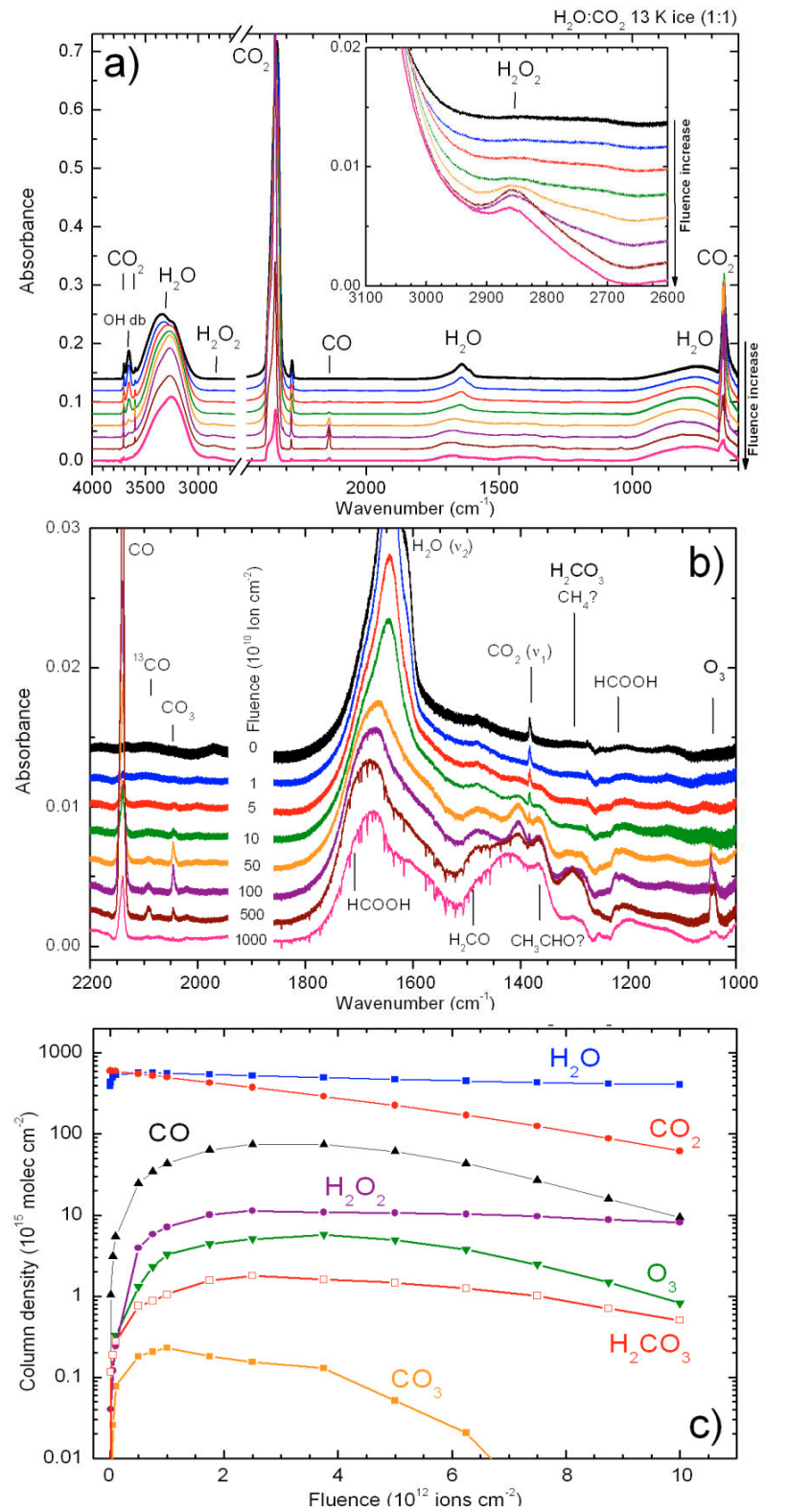

Fig. 1. a) Infrared spectra of $\mathrm{H}_{2} \mathrm{O}: \mathrm{CO}_{2} 13 \mathrm{~K}$ ice (1:1) before (top dark line) and after different irradiation fluences. b) Expanded view from 2200 to $1000 \mathrm{~cm}^{-1}$. c) Molecular column densities derived from the infrared spectra during the experiment. The lines are added to guide the eyes. 
newly formed $\mathrm{H}_{2} \mathrm{O}_{2}$ species due to the radiolysis of water inside the ice.

The region between 2200 to $1000 \mathrm{~cm}^{-1}$ is shown in detail in Fig. 1b. The ion fluence of each spectra is also given. In this spectral region several peaks grow as a function of fluence: they correspond to the appearance of new species formed by the $52 \mathrm{MeV} \mathrm{Ni}$ atoms bombardment, including $\mathrm{CO}, \mathrm{CO}_{3}$, $\mathrm{O}_{3}, \mathrm{H}_{2} \mathrm{CO}_{3}, \mathrm{H}_{2} \mathrm{CO}$ (tentative), and $\mathrm{HCOOH}$ (tentative). Some unidentified IR features appear around 1350 and $1450 \mathrm{~cm}^{-1}$.

The evolution of the column density as function of fluence is shown in Fig. 1c. The infrared band strengths used for determining the column density are listed in Table 1 . The column density of water presents a constant concentration of about $5 \times$ $10^{17}$ molecules $\mathrm{cm}^{-2}$, decreasing very slowly as the fluence increases. This is attributed to an approximate compensation between persisted water condensation (layering) and its disappearance by sputtering and dissociation.

The initial enhancement in the water column density maybe associated with the compaction effect produced by ion bombardment as discussed elsewhere (Palumbo 2006; Pilling et al. 2010). This compaction changes the band strength of some vibrational modes. Leto \& Baratta (2003) show that the band strength of water $v_{1}$ vibrational mode undergoes a $10 \%$ increase during the first ion impacts (low fluence) on ice in experiments employing ions with energy of dozens of keV. Another explanation may be a strong water layering just on the begging of irradiation. The $\mathrm{CO}_{2}$ abundance reaches its half value at a fluence of about $4 \times 10^{12}$ ions $\mathrm{cm}^{-2}$. The $\mathrm{CO}$ abundance increases very rapidly, reaching a maximum around $3-4 \times 10^{12}$ ions $\mathrm{cm}^{-2}$ and decreasing after that. The same behavior was observed for $\mathrm{O}_{3}, \mathrm{H}_{2} \mathrm{CO}_{3}$, and $\mathrm{CO}_{3}$, all produced by the radiolysis of $\mathrm{CO}_{2}$ inside the ice. For $\mathrm{O}_{3}, \mathrm{H}_{2} \mathrm{CO}_{3}$, and $\mathrm{CO}_{3}$, the column density maximum occurs at $4 \times 10^{12}, 3 \times 10^{12}$, and $1 \times 10^{12}$ ions $\mathrm{cm}^{-2}$, respectively. For $\mathrm{H}_{2} \mathrm{O}_{2}$ the maximum occurs at around $1 \times 10^{12}$ ions $\mathrm{cm}^{-2}$ and remains constant $\left(\sim 1 \times 10^{16}\right.$ molec $\left.\mathrm{cm}^{-2}\right)$ until the end of irradiation (up to a fluence of $1 \times 10^{13}$ ions $\mathrm{cm}^{-2}$ ).

The infrared spectra of $\mathrm{H}_{2} \mathrm{O}: \mathrm{CO}_{2}(10: 1)$ ice before and after different irradiation fluences up to $5 \times 10^{12}$ ions $\mathrm{cm}^{-2}$ are given in Fig. 2a. In contrast to $\mathrm{H}_{2} \mathrm{O}: \mathrm{CO}_{2}(1: 1)$, this ice does not present the $\mathrm{OH}$ dangling band at about $3650 \mathrm{~cm}^{-1}$, may come from the lower deposition rate or from the low amount of $\mathrm{CO}_{2}$ on ice. As suggested by Bouwman et al. (2007), the presence of impurities like $\mathrm{CO}$ and $\mathrm{CO}_{2}$ on amorphous water ices increases the icet's porosity and the $\mathrm{OH} \mathrm{db}$ becomes more prominent.

Figure $2 \mathrm{~b}$ shows details of the infrared spectra for regions between 2200 to $1000 \mathrm{~cm}^{-1}$. The wavenumber of some unidentified IR frequencies are given. The infrared peaks tentatively attributed to $\mathrm{H}_{2} \mathrm{CO}\left(\sim 1470 \mathrm{~cm}^{-1}\right)$ and $\mathrm{HCOOH}\left(\sim 1220 \mathrm{~cm}^{-1}\right)$ seem to be smaller than for $\mathrm{H}_{2} \mathrm{O}: \mathrm{CO}_{2}(10: 1)$ ice. As in the previous case the appearance of the $\mathrm{CO} v_{1}$ line at $2139 \mathrm{~cm}^{-1}$ is due to the $\mathrm{CO}_{2}$ radiolysis.

The variations in the column densities of the most abundant molecules observed during the irradiation of $\mathrm{H}_{2} \mathrm{O}: \mathrm{CO}_{2}$ ice $(10: 1)$ by $52 \mathrm{MeV} \mathrm{Ni}$ ions as function of fluence are given in Fig. 2c. Peaks due to $\mathrm{O}_{3}, \mathrm{H}_{2} \mathrm{CO}_{3}$, or $\mathrm{CO}_{3}$ molecules were not observed.

The infrared spectra of pure $\mathrm{H}_{2} \mathrm{O}$ and $\mathrm{CO}_{2}$ ices at $13 \mathrm{~K}$ for different $52 \mathrm{MeV}$ Ni fluences are shown in Figs. 3a and 4a, respectively. Upper curves indicate the virgin ice and figure insets display peak details of the newly formed species. For the radiolysis of pure water, only the formation of $\mathrm{H}_{2} \mathrm{O}_{2}$ (vibration mode $\left.v_{2}+v_{6}\right)$ is observed. In contrast, after the radiolysis of $\mathrm{CO}_{2}$ pure ice, at least three different compounds are formed: $\mathrm{CO}\left(v_{1}\right), \mathrm{O}_{3}\left(v_{3}\right)$, and $\mathrm{CO}_{3}\left(v_{1}\right)$ (see also Seperuelo Duarte et al. 2009).
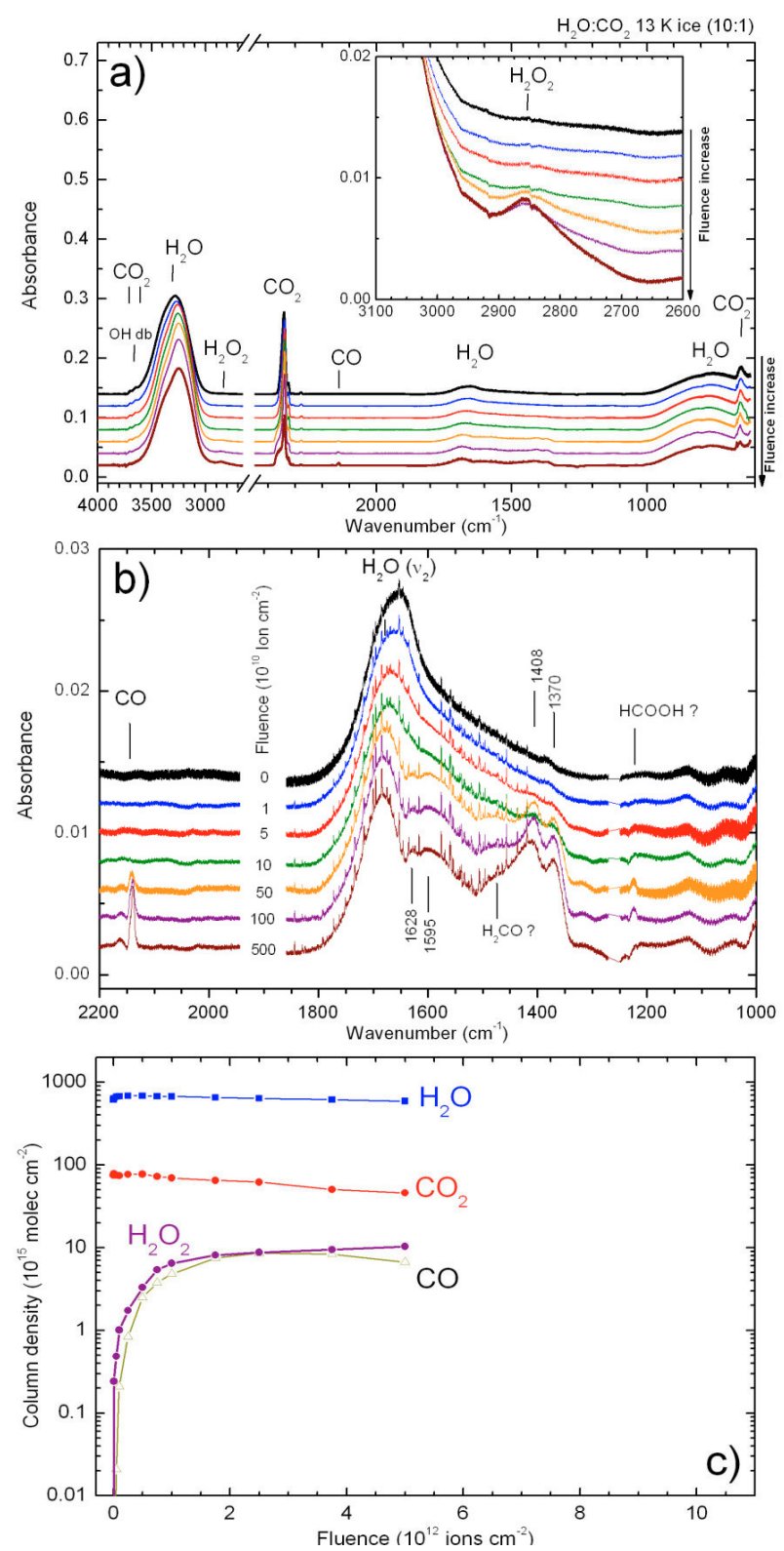

Fig. 2. a) Infrared spectra of $\mathrm{H}_{2} \mathrm{O}: \mathrm{CO}_{2} 13 \mathrm{~K}$ ice (10:1) before (top dark line) and after different irradiation fluences. b) Expanded view from 2200 to $1000 \mathrm{~cm}^{-1}$. c) Molecular column densities derived from the infrared spectra during the experiment.

Figure $3 \mathrm{~b}$ shows the evolution of the water column density derived from different vibration modes $\left(v_{1}, v_{2}\right.$ and $\left.v_{L}\right)$ and the column density of $\mathrm{H}_{2} \mathrm{O}_{2}$ as a function of ion fluence. The band strengths employed for water vibration modes $v_{2}\left(1650 \mathrm{~cm}^{-1}\right)$ was obtained by Gerakines et al. (1995) and $v_{L}\left(\sim 800 \mathrm{~cm}^{-1}\right)$ by Gibb et al. (2000). The evolution of $\mathrm{CO}_{2}$ column density, derived from different vibration modes $\left(v_{2}, v_{3}, v_{1}+v_{3}\right.$ and $\left.2 v_{2}+v_{3}\right)$, is given in Fig. $4 \mathrm{~b}$ : the distinct results are practically the same, as expected. The band strengths employed for $\mathrm{CO}_{2}$ vibration modes $v_{2}\left(670 \mathrm{~cm}^{-1}\right), 2 v_{2}+v_{3}\left(3599 \mathrm{~cm}^{-1}\right)$, and $v_{1}+v_{3}$ $\left(3708 \mathrm{~cm}^{-1}\right)$, were obtained by Gerakines et al. (1995). The column densities of the new species produced by radiolysis are also shown and will be discussed further.

The infrared absorption profile of water $\left(v_{1}\right)$ and carbon dioxide $\left(v_{3}\right)$ in pure and mixed $\left(\mathrm{H}_{2} \mathrm{O}: \mathrm{CO}_{2}(1: 1)\right)$ ices as a function of ion fluence are shown in Fig. 5. Upper panels (a and c) 

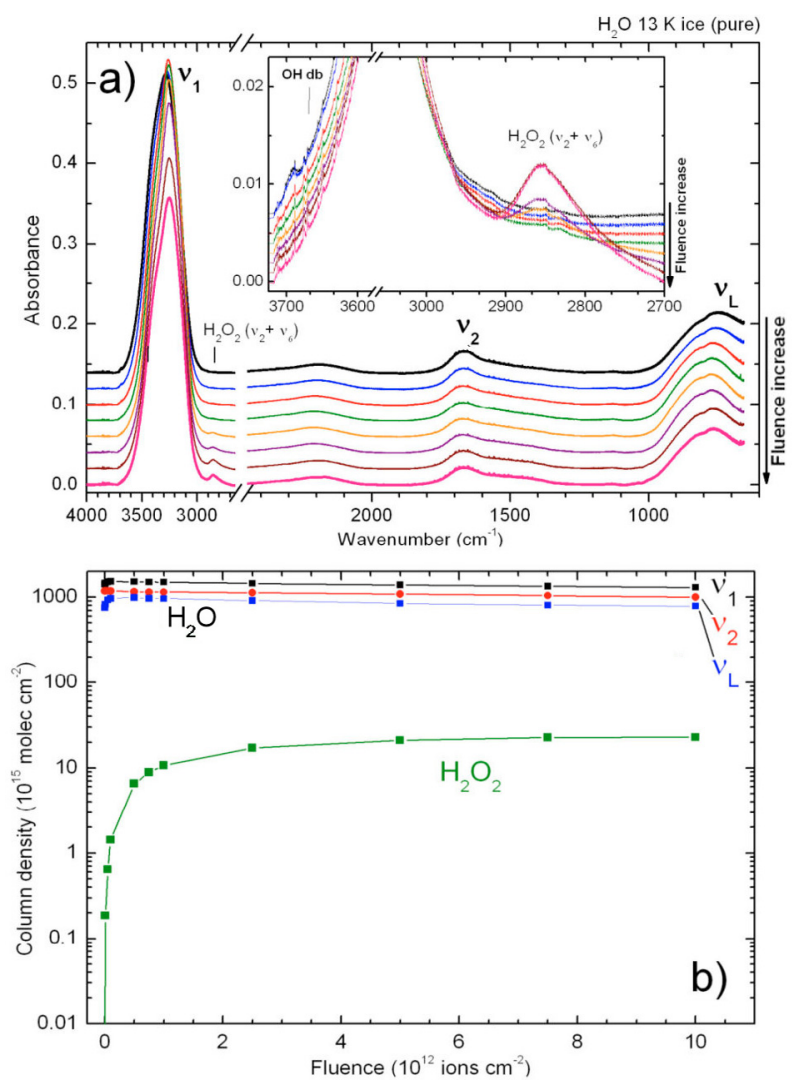

Fig. 3. a) Infrared spectra of pure water ice at $13 \mathrm{~K}$ obtained for different $52 \mathrm{MeV}$ Ni fluences. Inset figures present details of newly formed species. b) Molecular column densities derived from the infrared spectra during the experiment.

indicate pure ices. The selected IR features of mixed ice are illustrated in the bottom panels (b and d). In all panels the upper curves indicate the non-irradiated spectrum. Each spectrum has a small offset for clearer visualization. The bombardment by heavy ions slightly shifts the water $v_{1}$ vibration mode to low frequencies. As discussed by Paul et al. (1997), different water clusters are responsible for this IR, therefore this shifts suggests that small water clusters within the ice are being converted to larger cluster structures. Also large clusters may be less radiation sensitive than small clusters. This behavior is enhanced for mixed ices (Fig. 5b).

Figure $5 \mathrm{~b}$ presents the $\mathrm{OH}$ dangling bands $\left(\sim 3670 \mathrm{~cm}^{-1}\right)$ attributed to water molecules weakly adsorbed into micropores inside the ice (see Palumbo 2006). As the fluence increases, the micropores collapse and the $\mathrm{OH}$ dangling vibration modes decrease. We have shown previously (Pilling et al. 2010) that the ice compaction produced by heavy cosmic rays are at least 3 orders of magnitude higher than what is produced by $(0.8 \mathrm{MeV})$ protons.

The profile of the $v_{3}$ vibration mode of carbon dioxide appears to be very sensitive to the presence of water. It becomes very broad and also presents a shift toward the lower frequencies when water is mixed with $\mathrm{CO}_{2}$ (Fig. 5d). As the ion fluence increases, the $v_{3}$ band of $\mathrm{CO}_{2}$ becomes sharp and the peak moves toward higher frequencies, becoming similar to pure $\mathrm{CO}_{2}$ ice. A detailed discussion of the effects of $\mathrm{CO}_{2}$ and $\mathrm{H}_{2} \mathrm{O}$ on band profiles observed in mixed $\mathrm{H}_{2} \mathrm{O}: \mathrm{CO}_{2}$ ices is given elsewhere (Öberg et al. 2007).
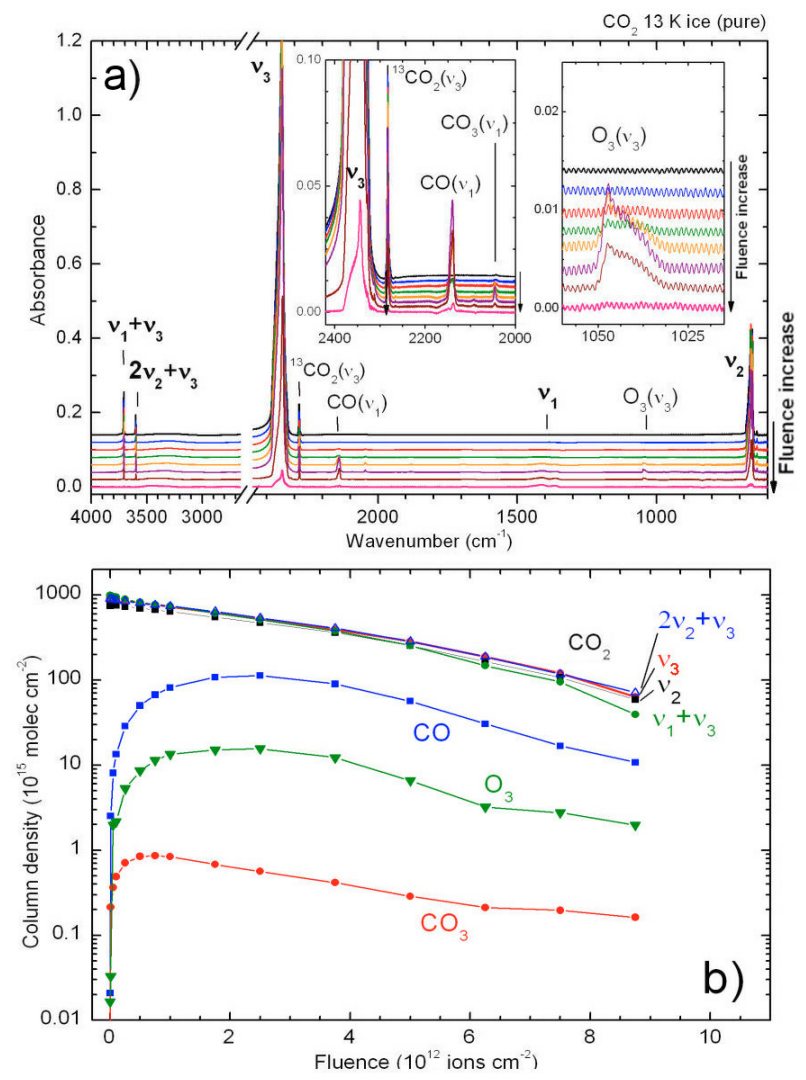

Fig. 4. a) Infrared spectra of pure $\mathrm{CO}_{2}$ ice at $13 \mathrm{~K}$ after different $52 \mathrm{MeV}$ $\mathrm{Ni}$ fluences. Inset figures present details of newly formed species. b) Molecular column densities derived from the infrared spectra during the experiment.
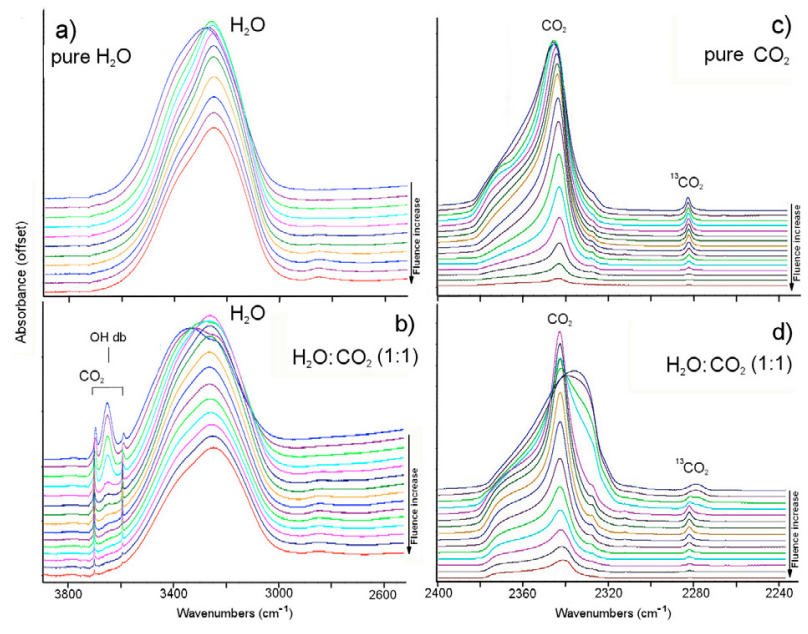

Fig. 5. Selected profile of water and $\mathrm{CO}_{2}$ vibration mode at different fluences up to $10^{13}$ ions $\mathrm{cm}^{-2}$. Pure water $v_{1}$ vibration mode a), water $v_{1}$ mode in mixed ices $\mathbf{b}$ ), pure $\mathrm{CO}_{2} v_{3}$ mode $\mathbf{c}$ ), and $\mathrm{CO}_{2} v_{3}$ mode in mixed ices d). See details in text.

\section{Discussion}

\subsection{Dissociation cross section}

As discussed previously by Seperuelo Duarte et al. (2009) and Pilling et al. (2010), the complex interaction between an 
Table 2. Dissociation cross section, radiochemical yield, and sputtering values of $\mathrm{H}_{2} \mathrm{O}$ and $\mathrm{CO}_{2}$ obtained from the radiolysis of pure water ice and mixed water- $\mathrm{CO}_{2}$ ices by $52 \mathrm{MeV}$ Ni ions.

\begin{tabular}{|c|c|c|c|c|c|c|c|c|}
\hline Species & $\begin{array}{l}\text { Mixture } \\
\left(\mathrm{H}_{2} \mathrm{O}: \mathrm{CO}_{2}\right)\end{array}$ & 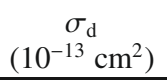 & $\begin{array}{c}-G_{\mathrm{d}} \\
\text { molec } / 100 \mathrm{eV}\end{array}$ & $\begin{array}{c}N_{\infty} \\
\left(10^{17} \mathrm{molec} \mathrm{cm}^{-2}\right)\end{array}$ & $\begin{array}{c}Y \\
\left(10^{4} \text { molec ion }^{-1}\right) \\
\end{array}$ & $\begin{array}{c}L^{\ddagger} \\
\left(10^{4} \text { molec ion }^{-1}\right) \\
\end{array}$ & $\begin{array}{c}N_{0} \\
\left(10^{17} \text { molec cm }^{-2}\right) \\
\end{array}$ & Model \\
\hline \multirow[t]{3}{*}{$\mathrm{H}_{2} \mathrm{O}$} & $(1: 0)$ & 1.1 & 7.48 & 12 & $1^{a}$ & 14 & 15 & 1 \\
\hline & $(10: 1)$ & $\sim 1$ & 4.90 & $\sim 4$ & $1^{a}$ & $\sim 5$ & 6.9 & 2 \\
\hline & $(1: 1)$ & 1.0 & 6.35 & 3.0 & $1^{a}$ & 4.0 & 5.9 & 3 \\
\hline \multirow[t]{5}{*}{$\mathrm{CO}_{2}$} & $(0: 1)$ & 1.8 & 6.90 & $\mathrm{NA}^{\dagger}$ & 2.2 & 0 & 9.1 & 4 \\
\hline & (1:1) & 1.6 & 7.84 & NA & $1.2^{b}$ & 0 & 6.2 & $5 \mathrm{a}$ \\
\hline & $(1: 1)$ & 2.1 & 10.3 & NA & $0^{c}$ & 0 & 6.2 & $5 b$ \\
\hline & $(10: 1)$ & $\sim 1$ & 6.35 & NA & $\sim 0.2^{d}$ & 0 & $\sim 0.8$ & $6 a$ \\
\hline & $(10: 1)$ & $\sim 0.7$ & 4.45 & NA & $0^{c}$ & 0 & $\sim 0.8$ & $6 \mathrm{~b}$ \\
\hline
\end{tabular}

Notes. ${ }^{(a)}$ Taken from Brown et al. (1984). ${ }^{(b)}$ Estimated to be a half of the value determined from pure $\mathrm{CO}_{2}$ ice. ${ }^{(c)}$ No $\mathrm{CO}_{2}$ sputtering. Assuming that the water layering is high enough to fully cover the $\mathrm{CO}_{2}$ molecules on the surface. ${ }^{(d)}$ Estimated to be a tenth of the value determined from pure $\mathrm{CO}_{2}$ ice. ${ }^{(\dagger)} \mathrm{NA}=$ Not applicable. ${ }^{(\ddagger)}$ For $\mathrm{H}_{2} \mathrm{O}$ : derived from $L=N_{\infty} \sigma_{\mathrm{d}}+Y$. For $\mathrm{CO}_{2}$ : assuming no layering from residual $\mathrm{CO}_{2}$.

energetic heavy ion with an ice target may be described through partial scenarios by considering successive aspects of the phenomenon. Since the impact of $52 \mathrm{MeV} \mathrm{Ni}$ atoms lies in the elec-

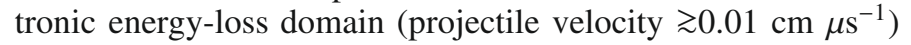
most of the deposited energy leads to excitation/ionization of target electrons (electronic energy loss regime). In turn, the electrons liberated from the ion track core $(0.3 \mathrm{~nm}$ of diameter for $52 \mathrm{MeV} \mathrm{Ni}$ atoms; Iza et al. 2006), transfer their energy to the surrounding condensed molecules $(\sim 3 \mathrm{~nm})$. The re-neutralization of the track proceeds concomitantly with the local temperature rise, leading to a possible sublimation.

The column density rate (a function of fluence) for each condensed molecular species during radiolysis can be written as

$\frac{\mathrm{d} N_{i}}{\mathrm{~d} F}=\sum_{j \neq i} \sigma_{\mathrm{f}, i j} N_{j}+L_{i}-\sigma_{\mathrm{d}, i} N_{i}-Y_{i} \Omega_{i}(F)$

where $\sum_{j} \sigma_{\mathrm{f}, i j} N_{j}$ represents the total molecular production rate of the $i$ species directly from the $j$ species, $L_{i}$ is the layering, $\sigma_{\mathrm{d}, i}$ the dissociation cross section, $Y_{i}$ the sputtering yield, and $\Omega_{i}(F)$ the relative area occupied by the $i$ species on the ice surface (see details in Pilling et al. 2010).

Considering that the analyzed compounds cannot react in a one-step process to form another species originally present in ice (i.e., $\sigma_{\mathrm{f}, i j} \approx 0$ ), for pure ices Eq. (2) can be written by

$N_{i}=\left(N_{0, i}-N_{\infty, i}\right) \exp \left(-\sigma_{\mathrm{d}, i} F\right)+N_{\infty, i}$

where $N_{\infty, i}=\left(L_{i}-Y_{i}\right) / \sigma_{\mathrm{d}, i}$ is the asymptotic value of column density at higher fluences owing to the presence of layering, and $N_{i}$ and $N_{0, i}$ are the column density of species $i$ at a given fluence and at the beginning of experiment, respectively. The layering yield is negligible $L_{\mathrm{CO} 2}=0$ for pure $\mathrm{CO}_{2}$.

For water-mixed ices, after the rapid ice compaction phase at the beginning of the irradiation, water layering tends to recover the ice surface, $\Omega_{i}(F) \rightarrow \delta_{i 1}$, progressively preventing the sputtering of $\mathrm{CO}_{2}$ molecules. At the end of these processes, the system of Eq. (2) is decoupled and can be solved analytically by

$N=\left(N_{0}-N_{\infty}\right) \exp \left(-\sigma_{\mathrm{d}} F\right)+N_{\infty}$ for $\mathrm{H}_{2} \mathrm{O}$

and

$N=N_{0} \exp \left(-\sigma_{\mathrm{d}} F\right)$ for $\mathrm{CO}_{2}$

where $N_{\infty}=(L-Y) / \sigma_{\mathrm{d}}$ is the asymptotic value of column density of water because of the presence of layering.
As discussed by Loeffler et al. (2005), the radiochemical formation yield $\left(G_{\mathrm{f}}\right)$ of a given compound per $100 \mathrm{eV}$ of deposited energy, at normal incidence, can be expressed in terms of the formation cross section $\left(\sigma_{\mathrm{f}}\right)$ and the stopping power $(S)$, in units of $\mathrm{eV} \mathrm{cm}^{2} /$ molec, as

$G_{\mathrm{f}}=100 \frac{\sigma_{\mathrm{f}}}{\mathrm{S}} \quad$ molecule per $100 \mathrm{eV}$.

This definition can be extended to the radiochemical dissociation (destruction) yield of a given compound per $100 \mathrm{eV}$ of deposited energy $\left(G_{\mathrm{d}}\right)$ by replacing the formation cross section in Eq. (6) by the negative value of the dissociation cross section $\left(-\sigma_{\mathrm{d}}\right)$. Therefore, negative $G_{\mathrm{d}}$ values indicate that molecules are being dissociated or destroyed after energy deposition into the ice.

By adopting the $S$ values from the stopping and ranges module of the SRIM2003 package (Ziegler 2003), the values of the radiation yield $G$ in the experiments can be determined and compared with the literature values. Table 2 presents the radiochemical destruction yields of $\mathrm{H}_{2} \mathrm{O}$ and $\mathrm{CO}_{2}$ per $100 \mathrm{eV}$ of deposited energy in each calculated model. The stopping powers of $52 \mathrm{MeV} \mathrm{Ni}$ ions for pure water ice and for $\mathrm{CO}_{2}$ ice are $S=1.4 \times$ $10^{-12} \mathrm{eV} \mathrm{cm} / \mathrm{H}_{2} \mathrm{O}$ and $2.6 \times 10^{-12} \mathrm{eV} \mathrm{cm} / \mathrm{CO}_{2}$, respectively. For mixed $\mathrm{H}_{2} \mathrm{O}: \mathrm{CO}_{2}$ ices, the stopping power is determined by interpolation between the pure ice values. We considered that the chemical changes during the irradiation does not affect the stopping power.

Figure 6 presents the fitting curves for the $\mathrm{H}_{2} \mathrm{O}$ and $\mathrm{CO}_{2}$ column densities employing Eq. (3) for pure ices, and Eqs. (4) and (5) for mixed ices. Numeric labels indicate parameters listed in Table 2. The $\mathrm{H}_{2} \mathrm{O}$ column density data level off around $N_{\infty} \simeq$ $1.2 \times 10^{18}, 4 \times 10^{17}$, and $3 \times 10^{17} \mathrm{molec} \mathrm{cm}^{-2}$ for pure water, $\mathrm{H}_{2} \mathrm{O}: \mathrm{CO}_{2}(10: 1)$, and $\mathrm{H}_{2} \mathrm{O}: \mathrm{CO}_{2}(1: 1)$ ice samples, respectively. The average value for the dissociation cross section of water, with Eq. (3), is $\sigma_{\mathrm{d}} \sim 1 \times 10^{-13} \mathrm{~cm}^{2}$. The sputtering yield for water measured by Brown et al. (1984) was extrapolated for the $52 \mathrm{MeV}$ Ni ions'impact as discussed in Pilling et al. (2010). The obtained value is $Y=1 \times 10^{4}$ molec per impact. The estimated average water layering of both experiments was within the $4-14 \times 10^{4}$ molec ion $^{-1}$ range, obtained from the relation $L=N_{\infty} \sigma_{\mathrm{d}}+Y$. The high value of water layering means that $\mathrm{CO}_{2}$ species in the mixed ices were recovered by an $\mathrm{H}_{2} \mathrm{O}$ film, and the $\mathrm{CO}_{2}$ ice sputtering yield is considered negligible in the current experiments; therefore, the data are adjusted directly by Eq. (5).

The fitting parameters (dissociation cross section, radiochemical yield, sputtering, layering, and the initial relative 


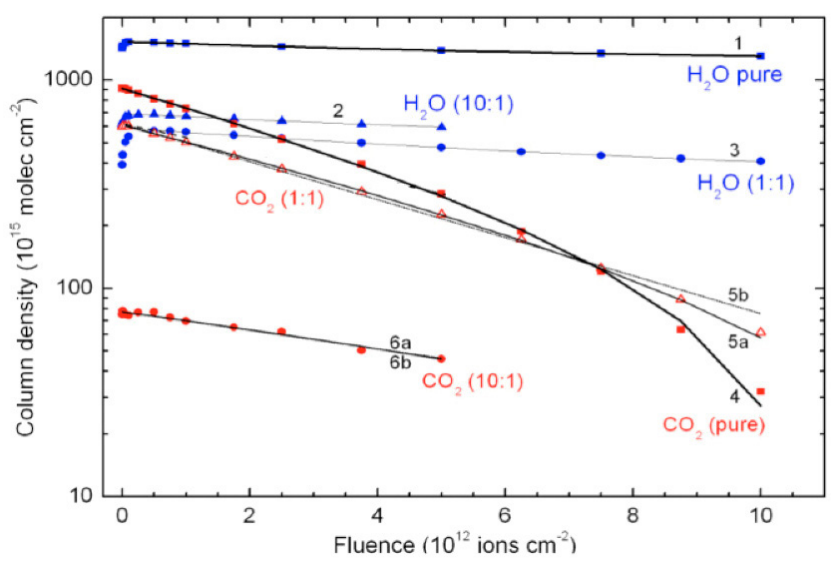

Fig. 6. Variation in the experimental column densities of $\mathrm{H}_{2} \mathrm{O}$ and $\mathrm{CO}_{2}$ as a function of fluence. Lines represent the fittings using Eq. (3) for pure ices and Eqs. (4) and (5) for mixed ices. The parameters models are listed in Table 2.

molecular abundance of each species in the ices) are listed in Table 2. Pure $\mathrm{H}_{2} \mathrm{O}$ and $\mathrm{CO}_{2}$ ice were fitted by the parameters of models 1 and 4, respectively. For water species the layering yield was determined by $L=N$ inf $+\sigma_{\mathrm{d}}+Y$. For $\mathrm{CO}_{2}$ species (model 4 to $6 b$ ), it is assumed there is no layering due to residual $\mathrm{CO}_{2}$. Model $5 \mathrm{a}$ is the fitting for the $\mathrm{CO}_{2}$ species in the mixed $\mathrm{H}_{2} \mathrm{O}: \mathrm{CO}_{2}$ ice (1:1), and the sputtered value was considered to be half the value from pure $\mathrm{CO}_{2}$ ice.

In model $5 \mathrm{~b}$ it is assumed that the water layering is high enough to fully cover the $\mathrm{CO}_{2}$ on the surface producing a negligible sputtering yield of $\mathrm{CO}_{2}$ molecules. From the comparison of models $5 \mathrm{a}$ and $\mathrm{b}$, we observe that the error in the dissociation cross section is lower than $30 \%$. Model 6a concerns the fitting for the $\mathrm{CO}_{2}$ species in the mixed $\mathrm{H}_{2} \mathrm{O}: \mathrm{CO}_{2}(10: 1)$ ice; the sputtering yield is considered to be a tenth of the value determined for pure $\mathrm{CO}_{2}$ ice.

From models 5, we observe that the sputtering can be precisely determined only for the ices monitored at higher ion fluences $\left(\sim 10^{13}\right.$ ion $\left.\mathrm{cm}^{-2}\right)$ since different sets between sputtering and dissociation cross section can be adjusted for the data with low fluences $\left(<5 \times 10^{12}\right.$ ions $\left.\mathrm{cm}^{-2}\right)$. Because of the degeneracy of such model for low ion fluence IR data, the error observed in the dissociation cross section on models 6 is about $40 \%$. Table 2 shows that the dissociation cross section at typical astrophysical ice $\left(\left[\mathrm{CO}_{2}\right] /\left[\mathrm{H}_{2} \mathrm{O}\right] \sim 0.05-0.1\right)$ is similar and equal to $\sim 1 \times 10^{-13} \mathrm{~cm}^{-2}$.

\subsection{Synthesis of new species}

The evolution of the column density of the newly formed species from $\mathrm{H}_{2} \mathrm{O}: \mathrm{CO}_{2}$ ices as a function of fluences is shown in Figs. $7 \mathrm{a}$ and $\mathrm{b}$. The ratio of $\mathrm{H}_{2} \mathrm{O}_{2}$ column density over its parent molecule $\left(\mathrm{H}_{2} \mathrm{O}\right)$ initial column density, $N_{\mathrm{H}_{2} \mathrm{O}_{2}} / N_{0, \mathrm{H}_{2} \mathrm{O}}$, as a function of fluence in 3 different water-concentration ices (pure $\mathrm{H}_{2} \mathrm{O}$ ice, $\sim 50 \%$ and $\sim 90 \%$ ) is given in Fig. 7a. The evolution of newly formed species $\mathrm{CO}, \mathrm{O}_{3}$, and $\mathrm{H}_{2} \mathrm{CO}_{3}$ from $\mathrm{CO}_{2}$-rich ices as a function of fluence is presented in Fig. 7b. The ratio $N_{i} / N_{0, \mathrm{CO}_{2}}$ indicates the column density ratio of a given produced species over its parent molecule's $\left(\mathrm{CO}_{2}\right)$ initial column density. Three different $\mathrm{CO}_{2}$-rich ices are analyzed (pure $\mathrm{CO}_{2}$ ice, $\sim 50 \%$ and

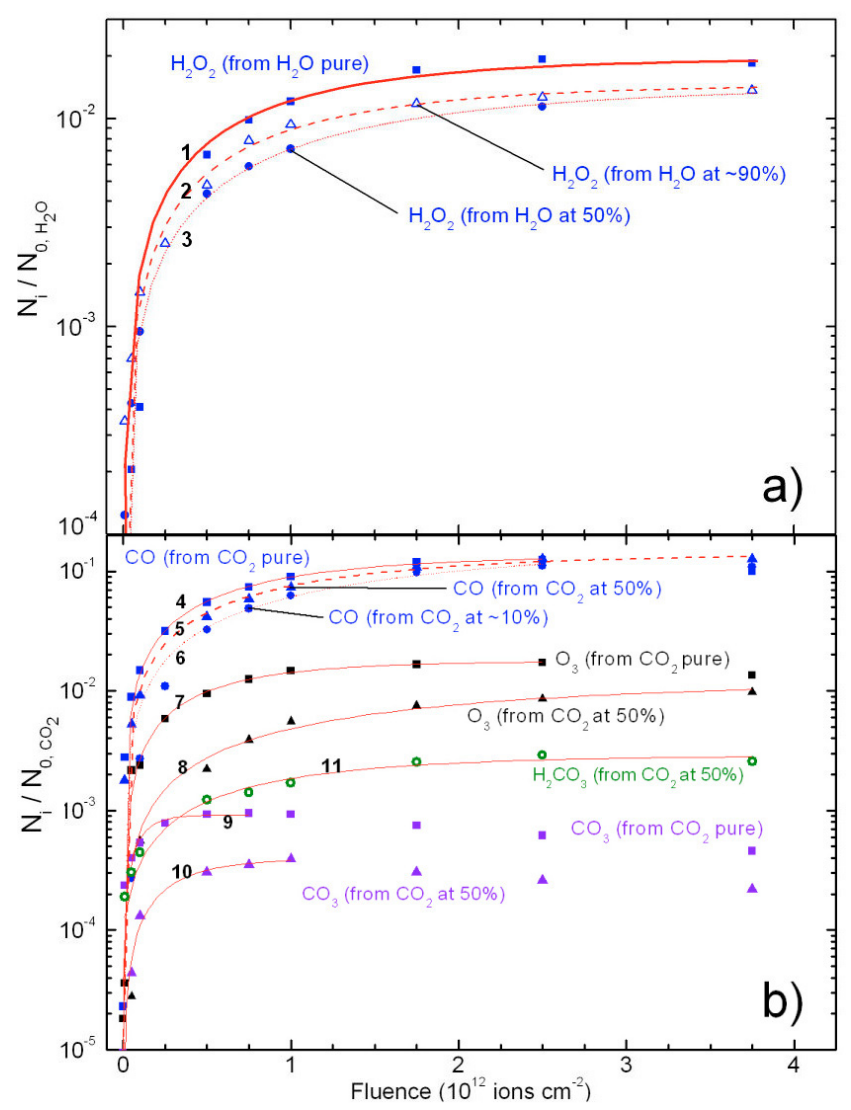

Fig. 7. The evolution of newly formed species from the bombardments of $\mathrm{H}_{2} \mathrm{O}: \mathrm{CO}_{2}$ ices by $52 \mathrm{MeV} \mathrm{Ni}$ as a function of fluence. a) Production of $\mathrm{H}_{2} \mathrm{O}_{2}$ from $\mathrm{H}_{2} \mathrm{O}$ molecules in different ices. b) Production of $\mathrm{CO}$, $\mathrm{O}_{3}, \mathrm{CO}_{3}$, and $\mathrm{H}_{2} \mathrm{CO}_{3}$ from $\mathrm{CO}_{2}$ molecules in different ices. The relative abundance of each parental species is indicated. The lines indicate the fittings using Eq. (11), and the model parameters are given in Table 3.

$\sim 10 \%$ ). The data was fitted by the simple exponential associate expression:

$N_{i} / N_{0, p}=A_{i}+B_{i}\left[1-\exp \left(-\sigma_{\mathrm{d}, i} F\right)\right]$

where $N_{i}$ and $N_{0, p}$ represents the column density of a given produced species $i$ over its parent molecule $p\left(\mathrm{H}_{2} \mathrm{O}\right.$ or $\left.\mathrm{CO}_{2}\right)$. Both $A_{i}$ and $B_{i}$ are constants that indicate the initial and the maximum amount (after radiolysis) of species $i$ on the ice, $\sigma_{\mathrm{f}, i}$ is the formation cross section, and $F$ is the ion fluence.

As the fluence increases, the number of produced molecules also increases and reaches a maximum. At this moment, the number of molecules produced by radiolysis of parental species is equal to the number of new molecules that possibly dissociate in the reverse reaction set (e.g. $p \rightleftarrows i+j+$ $k+\ldots)$. At the equilibrium the column density of the parental and daughter species, $N_{\text {eq, } p}$ and $N_{\text {eq, } i}$, respectively, are related by the expression:

$N_{\mathrm{eq}, p} \sigma_{\mathrm{f}, i}=N_{\mathrm{eq}, i} \sigma_{\mathrm{d}, i}$

where $\sigma_{\mathrm{f}, i}$ and $\sigma_{\mathrm{d}, i}$ is the formation cross section and dissociation cross section of daughter species $i$.

Since the column densities of daughter species $i$ are much lower than observed for parental species $p$, as a first approximation we have the following relation between them:

$\frac{N_{\mathrm{eq}, i}}{N_{0, p}}+\frac{N_{\mathrm{eq}, p}}{N_{0, p}} \simeq 1$. 
S. Pilling et al.: Radiolysis of water- $\mathrm{CO}_{2}$ ices by energetic heavy ions

Table 3. Formation and dissociation cross section of newly formed species from the radiolysis of $\mathrm{H}_{2} \mathrm{O}: \mathrm{CO}_{2}$ ices by $52 \mathrm{MeV} \mathrm{Ni}$ ions.

\begin{tabular}{llcccccc}
\hline \hline Species & $\begin{array}{l}\text { Parental } \\
\text { species }\end{array}$ & $\begin{array}{c}\text { Mixture } \\
{\left[\mathrm{H}_{2} \mathrm{O}: \mathrm{CO}_{2}\right]}\end{array}$ & $\begin{array}{c}\sigma_{\mathrm{f}} \\
\left(10^{-13} \mathrm{~cm}^{2}\right)\end{array}$ & $\begin{array}{c}\sigma_{\mathrm{d}} \\
\left(10^{-13} \mathrm{~cm}^{2}\right)\end{array}$ & $\begin{array}{c}G_{\mathrm{f}} \\
(\mathrm{molec} / 100 \mathrm{eV})\end{array}$ & $\begin{array}{c}-G_{\mathrm{d}} \\
(\mathrm{molec} / 100 \mathrm{eV})\end{array}$ & Model \\
\hline $\mathrm{H}_{2} \mathrm{O}_{2}$ & $\mathrm{H}_{2} \mathrm{O}$ & {$[1: 0]$} & 0.19 & 10 & 1.3 & 68.0 & 1 \\
& $\mathrm{H}_{2} \mathrm{O}$ & {$[10: 1]$} & 0.13 & 9.3 & 0.87 & 59.1 & 2 \\
$\mathrm{CO}$ & $\mathrm{H}_{2} \mathrm{O}$ & {$[1: 1]$} & 0.10 & 6.9 & 0.48 & 33.8 & 3 \\
& $\mathrm{CO}_{2}$ & {$[0: 1]$} & 1.8 & 11 & 6.8 & 42.1 & 4 \\
& $\mathrm{CO}_{2}$ & {$[1: 1]$} & 1.2 & 7.3 & 5.8 & 35.8 & 5 \\
$\mathrm{O}_{3}$ & $\mathrm{CO}_{2}$ & {$[10: 1]$} & 0.91 & 4.4 & 5.8 & 27.9 & 6 \\
& $\mathrm{CO}_{2}$ & {$[0: 1]$} & 0.27 & 16 & 1.1 & 61.3 & 7 \\
$\mathrm{CO}_{3}$ & $\mathrm{CO}_{2}$ & {$[1: 1]$} & 0.06 & 5.0 & 0.30 & 24.5 & 8 \\
& $\mathrm{CO}_{2}$ & {$[0: 1]$} & 0.09 & 97 & 0.33 & 372 & 9 \\
$\mathrm{H}_{2} \mathrm{CO}_{3}$ & $\mathrm{CO}_{2} \mathrm{O}$ and $\mathrm{CO}_{2}$ & {$[1: 1]$} & 0.01 & 31 & 0.06 & 152 & 10 \\
\hline
\end{tabular}

During the whole irradiation time, when a new species is being formed from the radiolysis of its parental species, a fraction of them are also being dissociated and possibly sputtered from the ice. This last effect is not being considered in this model. Since not all the parental molecules are converted into a given species, some could be sputtered from the ice, and others can react to produce different daughter species, the amount of parental molecule always decreases. Consequently, the column density of a given daughter species decreases after it reaches a maximum (equilibrium stage). This behavior can be observed for the evolution of $\mathrm{CO}_{3}$ species as a function of fluence (Fig. 7b).

Calling the maximum amount of newly formed species $i$ at the equilibrium as $N_{\infty, i}$ and using Eq. (9), we can express the constant $B_{i}$ of Eq. (7) by

$B_{i}=\frac{N_{\mathrm{eq}, i}}{N_{0, p}} \simeq 1-\frac{N_{\mathrm{eq}, p}}{N_{0, p}}$.

Moreover, considering that the number of initial daughter species $i$ is negligible $\left(A_{i}=0\right)$ and, after the combination of Eqs. (9) with (10), we rewrite Eq. (7) as:

$N_{i} / N_{0, p} \simeq \frac{1}{1+\frac{\sigma_{\mathrm{d}, i}}{\sigma_{\mathrm{f}, i}}}\left[1-\exp \left(-\sigma_{\mathrm{d}, i} F\right)\right]$

where $\sigma_{\mathrm{d}, i}$ and $\sigma_{\mathrm{f}, i}$ are the dissociation and formation cross section of species $i$.

The lines observed in the Figs. $7 \mathrm{a}$ and $\mathrm{b}$ were obtained by fitting the experimental data with Eq. (11). The proposed model is valid from the beginning of irradiation up to the fluence in which the column density reaches its maximum value. This indicates the equilibrium point between formation and destruction promoted by radiolysis. The formation and dissociation cross sections and the respective radiolysis yield determined for the newly formed species are given in Table 3 . We observe that $\mathrm{CO}$ presents the highest formation cross section among the newly formed species we studied.

\subsubsection{Hydrogen peroxide}

In recent years, different groups have studied the formation of hydrogen peroxide $\left(\mathrm{H}_{2} \mathrm{O}_{2}\right)$ by ion bombardment of pure water ice and mixed water- $\mathrm{CO}_{2}$ ices (Moore \& Hudson 2000; Strazzulla et al. 2003, 2005a,b; Baragiola et al. 2004; Loeffler et al. 2006; Gomis et al. 2004a,b). $\mathrm{H}_{2} \mathrm{O}_{2}$ was also observed from fast electron bombardment of pure water ices (Baragiola et al. 2005; Zheng et al. 2006) and also from low-energy (3-19 eV) electron bombardment (Pan et al. 2004).
Following Teolis et al. (2009), the most commonly $\mathrm{H}_{2} \mathrm{O}_{2}$ formation mechanisms involves the reaction between two $\mathrm{OH}$ radicals coming from the radiolysis of water molecules, as given by

$\mathrm{H}_{2} \mathrm{O} \stackrel{C R}{\longrightarrow} \mathrm{H}_{2} \mathrm{O}^{*} \longrightarrow \mathrm{OH}+\mathrm{H}$

$\mathrm{OH}+\mathrm{OH} \rightarrow \mathrm{H}_{2} \mathrm{O}_{2}$

where $C R$ denotes cosmic rays.

These $\mathrm{OH}$ radicals are strongly hydrogen-bonded to water molecules (Cooper et al. 2003), and it is not until above $80 \mathrm{~K}$ that they can diffuse within a water-ice lattice (Johnson \& Quickenden 1997). As pointed out by Cooper et al. (2008), energetic $\mathrm{OH}$ radicals can diffuse short distances along ion tracks and react at $10 \mathrm{~K}$, but bulk diffusion probably does not occur.

The decrease in the $\mathrm{H}_{2} \mathrm{O}_{2}$ production with temperature increase has been investigated by Zheng et al. (2006) and Loeffler et al. (2006). This indicates that electron scavenging may play a critical role in the radiation stability of $\mathrm{H}_{2} \mathrm{O}_{2}$ in pure waterice experiments. Moreover, Gomis et al. (2004a) have found that the $\mathrm{H}_{2} \mathrm{O}_{2}$ yields depended on projectile: ices irradiated with lowenergy $(30 \mathrm{keV}) \mathrm{C}^{+}, \mathrm{H}^{+}$, and $\mathrm{O}^{+}$ions produced more $\mathrm{H}_{2} \mathrm{O}_{2}$ at $77 \mathrm{~K}$ than $16 \mathrm{~K}$, while $\mathrm{N}^{+}$and $\mathrm{Ar}^{+}$had no temperature dependence on the $\mathrm{H}_{2} \mathrm{O}_{2}$ yield. The authors have also observed that the $\mathrm{H}$ irradiation produces a much lower quantity of $\mathrm{H}_{2} \mathrm{O}_{2}$ than for the other heavy ions, suggesting that the energy deposited by elastic collisions plays an important role in this process.

As discussed by Zheng et al. (2006) and Loeffler et al. (2006), there is another reaction sequence to produce hydrogen peroxide in astrophysical ices from the addition of oxygen atom (a product of the by the dissociation of oxidant compounds such as $\mathrm{O}_{2}, \mathrm{CO}, \mathrm{CO}_{2}, \mathrm{H}_{2} \mathrm{O}$, etc.) to water the molecule:

$\mathrm{O}+\mathrm{H}_{2} \mathrm{O} \rightarrow \mathrm{H}_{2} \mathrm{O}-\mathrm{O} \stackrel{\text { ionization }}{\longrightarrow} \mathrm{H}_{2} \mathrm{O}^{+}+\mathrm{O}^{-} \rightarrow \mathrm{H}_{2} \mathrm{O}_{2}$.

This reaction route involves an extra ionization stage triggered by $\mathrm{CR}, \mathrm{UV} / \mathrm{X}$-ray photons, or fast electrons to produce $\mathrm{H}_{2} \mathrm{O}_{2}$ (Loeffler et al. 2006), which implies a quadratic dependence on irradiation fluence being a secondary order reaction processes. In the present work we consider the $\mathrm{H}_{2} \mathrm{O}_{2}$ formation via oxygen addition to $\mathrm{H}_{2} \mathrm{O}$ negligible. Future investigations with isotopic labeling could help clarify this issue and quantify which fraction of $\mathrm{O}$ atoms produced from the dissociation of $\mathrm{CO}_{2}$ or $\mathrm{H}_{2} \mathrm{O}$ may react with $\mathrm{H}_{2} \mathrm{O}$ to form $\mathrm{H}_{2} \mathrm{O}_{2}$.

Table 4 presents the formation and dissociation cross section, as well as the radiochemical yield, of $\mathrm{H}_{2} \mathrm{O}_{2}$ obtained from the processing of pure water ice and mixed $\mathrm{H}_{2} \mathrm{O}: \mathrm{CO}_{2}$ ice. Both 
A\&A 523, A77 (2010)

Table 4. Comparison between the formation and dissociation cross section of $\mathrm{H}_{2} \mathrm{O}_{2}$ from the processing of pure $\mathrm{H}_{2} \mathrm{O}$ ices and $\mathrm{H}_{2} \mathrm{O}$ : $\mathrm{CO}_{2}$ ices.

\begin{tabular}{|c|c|c|c|c|c|c|c|c|}
\hline Ices & $\begin{array}{l}\text { Temp. } \\
\text { (K) }\end{array}$ & $\begin{array}{l}\text { Projectile } \\
\text { (Energy) }\end{array}$ & $\left(\begin{array}{c}\sigma_{\mathrm{f}} \\
\left(10^{-13} \mathrm{~cm}^{2}\right)\end{array}\right.$ & $\begin{array}{c}\sigma_{\mathrm{d}} \\
\left(10^{-13} \mathrm{~cm}^{2}\right)\end{array}$ & $\begin{array}{c}G_{\mathrm{f}} \\
(\mathrm{molec} / 100 \mathrm{eV})\end{array}$ & $\begin{array}{c}-G_{\mathrm{d}} \\
(\text { molec } / 100 \mathrm{eV})\end{array}$ & $\begin{array}{c}\mathrm{H}_{2} \mathrm{O}_{2} / \mathrm{H}_{2} \mathrm{O}^{\dagger} \\
(\%)\end{array}$ & Ref. \\
\hline $\mathrm{H}_{2} \mathrm{O}$ & 13 & $\mathrm{Ni}^{13+}(52 \mathrm{MeV})$ & 0.19 & 10 & 1.3 & 68.0 & 1.9 & [1] \\
\hline $\mathrm{H}_{2} \mathrm{O}: \mathrm{CO}_{2}(10: 1)$ & 13 & $\mathrm{Ni}^{13+}(52 \mathrm{MeV})$ & 0.13 & 9.3 & 0.87 & 59.1 & 1.6 & [1] \\
\hline $\mathrm{H}_{2} \mathrm{O}: \mathrm{CO}_{2}(1: 1)$ & 13 & $\mathrm{Ni}^{13+}(52 \mathrm{MeV})$ & 0.10 & 6.9 & 0.48 & 33.8 & 1.5 & [1] \\
\hline $\mathrm{H}_{2} \mathrm{O}$ & 16 & $\mathrm{H}^{+}(30 \mathrm{keV})$ & $\sim 0.001$ & 0.06 & 0.45 & 271 & 0.21 & [2] \\
\hline $\mathrm{H}_{2} \mathrm{O}$ & 16 & $\mathrm{C}^{+}(30 \mathrm{keV})$ & $\sim 0.001$ & 0.07 & 0.23 & 15.8 & 1.7 & [2] \\
\hline $\mathrm{H}_{2} \mathrm{O}$ & 16 & $\mathrm{~N}^{+}(30 \mathrm{keV})$ & $\sim 0.001$ & 0.09 & 0.19 & 17.1 & 1.6 & [2] \\
\hline $\mathrm{H}_{2} \mathrm{O}$ & 16 & $\mathrm{O}^{+}(30 \mathrm{keV})$ & 0.002 & 0.13 & 0.34 & 22.3 & 1.4 & [2] \\
\hline $\mathrm{H}_{2} \mathrm{O}$ & 16 & $\mathrm{Ar}^{+}(30 \mathrm{keV})$ & 0.002 & 0.07 & 1.34 & 46.8 & 2.2 & [2] \\
\hline $\mathrm{H}_{2} \mathrm{O}$ & 20 & $\mathrm{H}^{+}(100 \mathrm{keV})$ & $\sim 0.001$ & 0.20 & 0.38 & 76.1 & 0.75 & [3] \\
\hline $\mathrm{H}_{2} \mathrm{O}$ & 16 & $\mathrm{H}^{+}(200 \mathrm{keV})$ & $\sim 0.001$ & 0.09 & 0.49 & 43.9 & 1.2 & [4] \\
\hline $\mathrm{H}_{2} \mathrm{O}$ & 16 & $\mathrm{He}^{+}(200 \mathrm{keV})$ & 0.003 & 0.13 & 0.37 & 16.1 & 2.4 & [4] \\
\hline $\mathrm{H}_{2} \mathrm{O}$ & 16 & $\mathrm{Ar}^{2+}(400 \mathrm{keV})$ & $\sim 0.001$ & 0.04 & 0.07 & 2.79 & 6.0 & [4] \\
\hline
\end{tabular}

Notes. The formation and dissociation radiochemical yields of $\mathrm{H}_{2} \mathrm{O}_{2}$, as well the asymptotic $\mathrm{H}_{2} \mathrm{O}_{2} / \mathrm{H}_{2} \mathrm{O}$ ratio in each experiment, are also given. Asymptotic value; [1] this study; [2] Gomis et al. (2004a); [3] Loeffler et al. (2006); [4] Gomis et al. (2004b).

the formation and dissociation cross section of $\mathrm{H}_{2} \mathrm{O}_{2}$ decrease as the relative abundance of $\mathrm{H}_{2} \mathrm{O}$ in the ice decreases, a consequence of greater averaged distance between parental species. From Fig. 7 we also observe that the presence of $\mathrm{CO}_{2}$ inside the ice decreases the $\mathrm{H}_{2} \mathrm{O}_{2} / \mathrm{H}_{2} \mathrm{O}$ ratio. This points in the opposite direction to the results observed from the irradiation of water- $\mathrm{CO}_{2}$ by light ions (Strazzulla et al. 2005b; Moore \& Hudson 2000). From Table 4 we observe that the formation cross section of $\mathrm{H}_{2} \mathrm{O}_{2}$ from the bombardment of pure water ice by heavy and energetic ions is $10^{5}$ higher than the value obtained by the impact of light or/and slower projectiles.

The asymptotic value for the $\mathrm{H}_{2} \mathrm{O}_{2} / \mathrm{H}_{2} \mathrm{O}$ ratio presents a slight reduction with the enhancement of initial $\mathrm{CO}_{2}$ in the ice. This clearly shows that $\mathrm{H}_{2} \mathrm{O}_{2}$ formation via $\mathrm{O}+\mathrm{H}_{2} \mathrm{O}$, in which the oxygen comes from another oxidant compound, such as $\mathrm{CO}_{2}$, is indeed a second-order process (Loeffler et al. 2006). Our value is about 8 times higher than for irradiation with $30 \mathrm{keV}$ protons, but very similar to the asymptotic values obtained after the impact with other $30 \mathrm{keV}$ ions, such as $\mathrm{C}^{+}, \mathrm{N}^{+}$, and $\mathrm{O}^{+}$(Gomis et al. 2004a). A comparison between our radiochemical yield and cross sections with literature have revealed higher values for both the formation and destruction of $\mathrm{H}_{2} \mathrm{O}_{2}$ during bombardments of ices by heavy and energetic ions. In other words, the chemical processing is enhanced by the processing of ices by heavy and energetic and highly charged ions in comparison to light ions.

Hydrogen peroxide has been found on the surface of Europa by identifying both an absorption feature at $3.5 \mu \mathrm{m}$ in the Galileo NIMS spectra and looking at the UV spectrum taken by the Galileo ultraviolet spectrometer (UVS) (Carlson et al. 1999). Following the authors, the relative abundance with respect to water in Europa is $\mathrm{H}_{2} \mathrm{O}_{2} / \mathrm{H}_{2} \mathrm{O} \sim 0.001(=0.1 \%)$. As the Jupiter satellite is immersed in the intense magnetosphere of the planet, the authors also suggest that radiolysis is the dominant formation mechanism of such a molecule. As discussed by Hendrix et al. (1999), this compound has also been detected on the other icy Galilean moons of Jupiter in the ultraviolet, such as Callisto and Ganymede, although it is less evident on the darker satellites than on Europa. The estimated ratio on Ganymede is $\mathrm{H}_{2} \mathrm{O}_{2} / \mathrm{H}_{2} \mathrm{O} \sim 0.003$ (=0.3\%) (Hendrix et al. 1999).

Hydrogen peroxide has also been suggested to be present in icy mantles on grains in dense clouds as pointed out
Boudin et al. (1998). Based on observations and laboratory studies, they have estimated the relative abundance with respect to water at the dense molecular cloud NGC 7538:IRS 9 of $\mathrm{H}_{2} \mathrm{O}_{2} / \mathrm{H}_{2} \mathrm{O} \sim 0.05$ (=5\%). Following the authors, hydrogen peroxide can be also produced on grain surfaces via the hydrogenation of molecular oxygen.

\subsubsection{Ozone}

Ozone $\left(\mathrm{O}_{3}\right)$ has been detected after irradiation of mixed $\mathrm{H}_{2} \mathrm{O}: \mathrm{CO}_{2}(1: 1)$ ices and pure $\mathrm{CO}_{2}$ ice at $16 \mathrm{~K}$ by $1.5-200 \mathrm{keV}$ ions (protons and $\mathrm{He}^{+}$) (Strazzulla et al. 2005a,b). According to these authors, the $\mathrm{O}_{3}$ production from radiolysis is highly attenuated for $\mathrm{CO}_{2}$-poor mixed ices, e.g. for $\mathrm{H}_{2} \mathrm{O} / \mathrm{CO}>2.5$. We do not observe ozone among the compounds produced by radiolysis of $\mathrm{H}_{2}: \mathrm{CO}_{2}(10: 1)$ ice. The presence of ozone is also observed after the irradiation of $\mathrm{CO}: \mathrm{O}_{2}(1: 1)$ ice by $60 \mathrm{keV} \mathrm{Ar}^{++}$and $3 \mathrm{keV} \mathrm{He}^{+}$ (Strazzulla et al. 1997). The authors suggest that the detection of ozone and the absence of suboxides (e.g. $\mathrm{C}_{2} \mathrm{O}$ and $\mathrm{C}_{3} \mathrm{O}$ ) in interstellar grains would indicate a dominance of molecular oxygen in grain mantles. These suboxides have not been detected in our experiments.

Seperuelo Duarte et al. (2010) bombarded pure CO ice with $50 \mathrm{MeV} \mathrm{Ni}{ }^{+13}$ and observed ozone and several suboxides $\left(\mathrm{C}_{2} \mathrm{O}\right.$, $\mathrm{C}_{3} \mathrm{O}_{2}, \mathrm{C}_{5} \mathrm{O}_{2}$ ) among the radiolysis products. They have determined the ozone formation cross section is $3 \times 10^{-16} \mathrm{~cm}^{2}$. Ozone and suboxides were also observed after irradiation of pure $\mathrm{CO}$ ice at $16 \mathrm{~K}$ by $200 \mathrm{keV}$ protons (Palumbo et al. 2008).

We detected ozone after the radiolysis of pure $\mathrm{CO}_{2}$ ice and mixed $\mathrm{H}_{2} \mathrm{O}: \mathrm{CO}_{2}(1: 1)$ ice by $52 \mathrm{MeV} \mathrm{Ni}^{+13}$. The determined formation cross section of ozone is $\sigma_{\mathrm{O} 3}=0.27 \times 10^{-13} \mathrm{~cm}^{2}$ in pure $\mathrm{CO}_{2}$ ice and $0.06 \times 10^{-13} \mathrm{~cm}^{2}$ in $\mathrm{H}_{2} \mathrm{O}: \mathrm{CO}_{2}$ ice. These values indicate that the $\mathrm{O}_{3}$ formation cross section decreases as the relative abundance of the parental $\mathrm{CO}_{2}$ compound in the ice declines. The value obtained for ozone formation via pure $\mathrm{CO}_{2}$ is 2 times higher than the value determined previously in similar radiolysis experiments involving pure ${ }^{18} \mathrm{CO}_{2}$ irradiated by $46 \mathrm{MeV} 58 \mathrm{Ni}^{+11}$ (Seperuelo Duarte et al. 2009).

In the solar system, ozone has been observed on Ganymede (Noll et al. 1996) and on Saturn's satellites Rhea and Dione (Noll et al. 1997). Following Strazzulla et al. (2005a) ozone could be formed where fresh $\mathrm{CO}_{2}$-rich layers are exposed to radiation. 
The strong silicate absorption band around $1040 \mathrm{~cm}^{-1}$ makes the observation of ozone in interstellar medium very difficult. However, the appearance of ozone seems conceivable, since it is observed in laboratory experiments involving the processing of astrophysical ices analogs.

\subsubsection{Carbon trioxide}

Carbon trioxide $\left(\mathrm{CO}_{3}\right)$ has been observed after the UV processing of pure $\mathrm{CO}_{2}, \mathrm{CO}$ and $\mathrm{O}_{2} 10 \mathrm{~K}$ ices (Gerakines et al. 1996; Gerakines \& Moore 2001) and also on radiolysis of pure $\mathrm{CO}_{2}$ by $0.8 \mathrm{MeV}$ protons (Gerakines \& Moore 2001) and $1.5 \mathrm{keV}$ protons (Brucato et al. 1997). The bombardment of mixed $\mathrm{H}_{2} \mathrm{O}: \mathrm{CO}_{2}$ ices by $3 \mathrm{keV} \mathrm{He}{ }^{+}, 1.5 \mathrm{keV}$, and $0.8 \mathrm{MeV}$ protons also shows the formation of $\mathrm{CO}_{3}$. Furthermore, $\mathrm{H}_{2} \mathrm{CO}_{3}$ and possibly $\mathrm{O}_{3}$ are produced (Brucato et al. 1997; Moore \& Khanna 1991).

Seperuelo Duarte et al. (2009) have observed this species in the radiolysis of of $\mathrm{C}^{18} \mathrm{O}_{2}$ by $46 \mathrm{MeV}^{58} \mathrm{Ni}^{11+}$ up to a final fluence of $1.5 \times 10^{13} \mathrm{~cm}^{-2}$. In our measurement the formation cross section of $\mathrm{CO}_{3}$ from radiolysis of pure $\mathrm{CO}_{2}$ ice is $0.08 \times$ $10^{-13} \mathrm{~cm}^{-2}$, roughly 5 times lower than the value obtained previously by Seperuelo Duarte et al. (2009). This value presents a decrease in water in the ice, as observed for $\mathrm{H}_{2} \mathrm{O}: \mathrm{CO}_{2}(1: 1)$ ice (see Table 3). The formation cross section of $\mathrm{CO}$ in our experiments on pure $\mathrm{CO}_{2}$ is roughly the same as the one determined by Seperuelo Duarte et al. (2009).

The $\mathrm{CO}_{3}$ destruction cross section due to radiolysis is larger than the other compounds formed into the ices. To increase the accuracy of the cross sections, the next measurements should cover large data sets inside the fluence range between $1-10 \times$ $10^{11}$ ions $\mathrm{cm}^{-2}$. In contrast to UV photolysis of pure $\mathrm{CO}_{2}$ ices (Gerakines et al. 1996), we do not observe the formation of $\mathrm{C}_{3} \mathrm{O}$ at $2243 \mathrm{~cm}^{-1}$ from the radiolysis of $\mathrm{CO}_{2}$ ices.

Despite the prediction of $\mathrm{CO}_{3}$ among the compounds in the processed astrophysical ices (e.g. Elsila et al. 1997; Allamandola et al. 1999), this species has not yet been detected conclusively in space (Elsila et al. 1997; Ferrante et al. 2008).

\subsubsection{Carbonic acid}

Carbonic acid $\left(\mathrm{H}_{2} \mathrm{CO}_{3}\right)$ has been observed in several experiments involving ion bombardment of $\mathrm{H}_{2} \mathrm{O}: \mathrm{CO}_{2}$ ices (Moore \& Khanna 1991; DelloRusso et al. 1993; Brucato et al. 1997). It was also observed after the radiolysis of pure $\mathrm{CO}_{2}$ ice at $10 \mathrm{~K}$ by $1.5 \mathrm{keV}$ protons (Brucatto et al. 1997), indicating that implanted hydrogen ions are incorporated in the target to form new bonds to produce $\mathrm{H}_{2} \mathrm{CO}_{3}$.

As discussed by Gerakines et al. (2000), the formation of $\mathrm{H}_{2} \mathrm{CO}_{3}$ from ion bombardment of $\mathrm{H}_{2} \mathrm{O}: \mathrm{CO}_{2}$ ices is ruled by two main reaction schemes. First, the direct dissociation of $\mathrm{H}_{2} \mathrm{O}$ molecules by incoming projectile,

$$
\mathrm{H}_{2} \mathrm{O} \stackrel{C R}{\longrightarrow} \mathrm{OH}+\mathrm{H}^{+}+e^{-} \text {, }
$$

where products such as $\mathrm{H}_{2}, \mathrm{H}_{2} \mathrm{O}_{2} ; \mathrm{H}_{3} \mathrm{O}^{+}$, and $\mathrm{HO}_{2}$ are eventually formed by reactions involving the primary dissociation products. The next step is the electron attachment to $\mathrm{CO}_{2}$ or $\mathrm{OH}$ producing reactive compounds that quickly react with each other to produce bicarbonate $\left(\mathrm{HCO}_{3}^{-}\right)$:

$$
\mathrm{CO}_{2}^{-}+\mathrm{OH} \longrightarrow \mathrm{HCO}_{3}^{-} \text {and/or } \quad \mathrm{CO}_{2}+\mathrm{OH}^{-} \longrightarrow \mathrm{HCO}_{3}^{-} \text {. }
$$

Finally, bicarbonate reacts with a proton to produce $\mathrm{H}_{2} \mathrm{CO}_{3}$ :

$\mathrm{HCO}_{3}^{-}+\mathrm{H}^{+} \longrightarrow \mathrm{H}_{2} \mathrm{CO}_{3}$.
From the evolution of the IR peak at $1307 \mathrm{~cm}^{-1}$ during the radiolysis of $\mathrm{H}_{2} \mathrm{O}: \mathrm{CO}_{2}(1: 1)$ ice by $52 \mathrm{MeV} \mathrm{Ni}$ ions, we determined the formation and the dissociation cross section of $\mathrm{H}_{2} \mathrm{CO}_{3}$ and the values obtained are $3.0 \times 10^{-15} \mathrm{~cm}^{2}$ and $9.9 \times 10^{-13} \mathrm{~cm}^{2}$, respectively. This formation cross section is 8 orders of magnitude higher than the one derived from the UV photolysis of $\mathrm{H}_{2} \mathrm{O}: \mathrm{CO}$ (1:1) ices at $18 \mathrm{~K}$ (Gerakines et al. 2000), indicating that heavy ion processing of astrophysical ice analogs is very efficient to form $\mathrm{H}_{2} \mathrm{CO}_{3}$ compared to UV photons.

$\mathrm{H}_{2} \mathrm{CO}_{3}$ is thermally stable at $200 \mathrm{~K}$, higher than the sublimation temperature of $\mathrm{H}_{2} \mathrm{O}$. As discussed by Peeters et al. (2008), ices containing both $\mathrm{H}_{2} \mathrm{O}$ and $\mathrm{CO}_{2}$ have been found on a variety of surfaces such as those of Europa, Callisto, Iapetus, and Mars, where processing by magnetospheric ions or the solar wind and energetic solar particles may lead to the formation of $\mathrm{H}_{2} \mathrm{CO}_{3}$.

The astrophysical significance of solid carbonic acid has been extensively discussed elsewhere (e.g. Khanna et al. 1994; Brucato et al. 1997; Strazzullla et al. 1996). $\mathrm{H}_{2} \mathrm{CO}_{3}$ has been suggested to be present at the surface of several solar system bodies with sufficient amounts of $\mathrm{CO}_{2}$ such as Galilean satellites of Jupiter (Wayne 1995; McCord et al. 1997; Johnson et al. 2004) and comets (Hage et al. 1998). Europa, Ganymede, and Callisto all exhibit high surface $\mathrm{CO}_{2}$ abundances and these satellites are heavily bombarded by energetic magnetospheric particles, galactic cosmic rays, and solar radiation.

It has been suggested that the $3.8 \mu \mathrm{m}$ feature in NIMS spectra of Ganymede and Callisto arise from $\mathrm{H}_{2} \mathrm{CO}_{3}$ (Johnson et al. 2004; Hage et al. 1998). Following Carlson et al. (2005) the relative abundance of carbonic acid with respect to $\mathrm{CO}_{2}$ in Callisto is $\mathrm{H}_{2} \mathrm{CO}_{3} / \mathrm{CO}_{2} \sim 0.01$.

The presence of $\mathrm{H}_{2} \mathrm{CO}_{3}$ in interstellar ices seems also to be very likely (Whittet et al. 1996) not only in the solid phase but also in gas phase (Hage et al. 1998). For the quiescent cloud medium toward the background field star Elias 16, the expected $\mathrm{H}_{2} \mathrm{CO}_{3}$ column density could be as much as $4.6 \times$ $10^{16}$ molec cm $\mathrm{cm}^{-2}$, corresponding roughly $1 \%$ of the $\mathrm{CO}_{2}$ or $0.2 \%$ of the total $\mathrm{H}_{2} \mathrm{O}$ in this line of sight (Whittet et al. 1998).

As discussed by Zheng \& Kaiser (2007), in the history of Mars there might be a high concentration of carbonic acid produced by radiolysis of surface $\mathrm{H}_{2} \mathrm{O}: \mathrm{CO}_{2}$ ices. Without a dense atmosphere and magnetic field, Mars lacks the power to attenuate penetrating energetic solar particles, energetic cosmic rays or any type of high-energy particles. Following Westall et al. (1998), if available in sufficient concentrations, carbonic acid could potentially dissolve metal ores and catalyze chemical reactions, and its presence on Mars may also lead to the existence of limestone $\left(\mathrm{CaCO}_{3}\right)$, magnesite $\left(\mathrm{MgCO}_{3}\right)$, dolomite $\left(\mathrm{CaMg}\left(\mathrm{CO}_{3}\right)_{2}\right)$, and siderite $\left(\mathrm{FeCO}_{3}\right)$.

\section{Astrophysical implication}

Figure 8 presents the total flux of heavy ions $(12 \lessgtr Z \lesssim 29)$ with energy between $0.1-10 \mathrm{MeV} / \mathrm{u}$ inside solar system as a function of distance to the Sun. Both Galactic cosmic rays (GCR) and energetic solar particles are displayed. The integrated flux of heavy and energetic solar ions (black square) at Earth Orbit were measured by Mewaldt et al. (2007). Starting from the solar photosphere abundance and the assumption that elements with a first ionization potential of less than $10 \mathrm{eV}$ are more abundant in the energetic solar particles than in the photosphere by a factor of 4.5 (Grevesse et al. 1996) at Earth's orbit, the integrated flux of heavy and energetic solar particles $\left(\phi_{\mathrm{HSW}}\right)$ with energies around $0.1-10 \mathrm{MeV} / \mathrm{u}$ was found to be about $1.4 \times$ $10^{-2} \mathrm{~cm}^{-2} \mathrm{~s}^{-1}$ (black square in Fig. 8). 


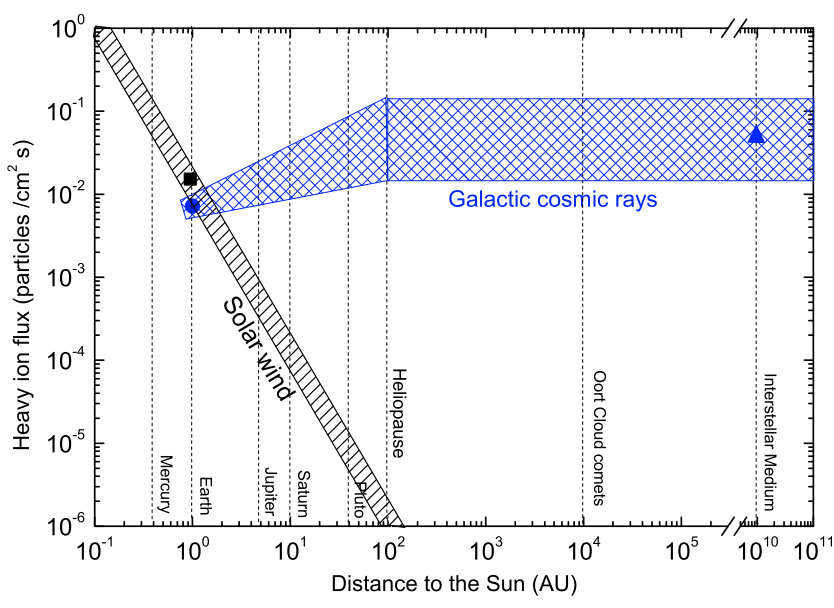

Fig. 8. Estimated value of the integrated flux of heavy ions $(12 \lessgtr Z \lesssim 29)$ with energy between $0.1-10 \mathrm{MeV} / \mathrm{u}$ inside solar system and at interstellar medium as a function of distance to the Sun. Both Galactic cosmic rays and energetic solar particles are displayed. Square: integrated flux of energetic solar particles. Circle and triangle: integrated flux of cosmic rays.

The heavy-ion integrated flux at Earth orbit from galactic sources (heavy cosmic rays) was calculated by using the lunar-GCR particle model of Reedy \& Arnold (1972) (see also Fig. 3.20 of Vaniman et al. 1991) and taking into account the relative elemental abundances of $12<Z<29$ atoms at $1 \mathrm{AU}$ (Simpson 1983; Drury et al. 1999). The value obtained was $\sim 7 \times$ $10^{-3} \mathrm{~cm}^{-2} \mathrm{~s}^{-1}$ (blue circle in Fig. 8). Assuming that the fluxes of solar wind and energetic solar particles are inversely proportional to the squared distance, this value can be determined as a function of distance up to the heliopause ( $\sim 100 \mathrm{AU})$ (i.e. the boundary between the solar wind domain and the interstellar medium).

The average heavy nuclei cosmic ray flux $\left(\phi_{\mathrm{HCR}}\right)$ in interstellar medium was estimated by Pilling et al. (2010), who considered the value of $\phi_{\mathrm{HCR}} \sim 5 \times 10^{-2} \mathrm{~cm}^{-2} \mathrm{~s}^{-1}$ (blue triangle in Fig. 8). This value was instead the same as at the outer border of heliopause. An error region (dashed area) was introduced in the Fig. 8 to take the uncertainty of these estimations into account.

The value of integrated flux of heavy ions with energies around $0.1-10 \mathrm{MeV} / \mathrm{u}$ from galactic sources and energetic solar particles are comparable at the Mars orbit ( 1.5 AU). However at the orbits of Jupiter, Saturn, Uranus, and Pluto and at the heliopause border, $\phi_{\mathrm{HCR}} / \phi_{\mathrm{HSW}} \sim 2 \times 10^{1}, 1 \times 10^{2}, 7 \times 10^{2}, 3 \times 10^{3}$ and $2 \times 10^{4}$, respectively. The total flux of heavy particles with energy between $0.1-10 \mathrm{MeV} / \mathrm{u}$ at Oort cloud distance was assumed to be the same as expected in the interstellar medium.

Considering the estimated flux of heavy particles of energetic solar particles $\left(\phi_{\mathrm{HSW}}\right)$ and of heavy nuclei cosmic rays $\left(\phi_{\mathrm{GCR}}\right)$, as well as of the determined dissociation cross section $\left(\sigma_{\mathrm{d}}\right)$, we can calculate the typical molecular half-lives of frozen molecules in astrophysical surfaces, caused by heavy particles by the expression (see Pilling et al. 2010):

$t_{1 / 2} \approx \frac{\ln 2}{\left(\phi_{H S W}+\phi_{H C R}\right) \times \sigma_{\mathrm{d}}} \quad\left[\mathrm{s}^{-1}\right]$.

It is worth noting that the present experiments were performed at the low temperature of $13 \mathrm{~K}$, the temperature that is adequate for ices in the interstellar medium. Therefore it is useful to compare IR spectra of interstellar and laboratory ices as

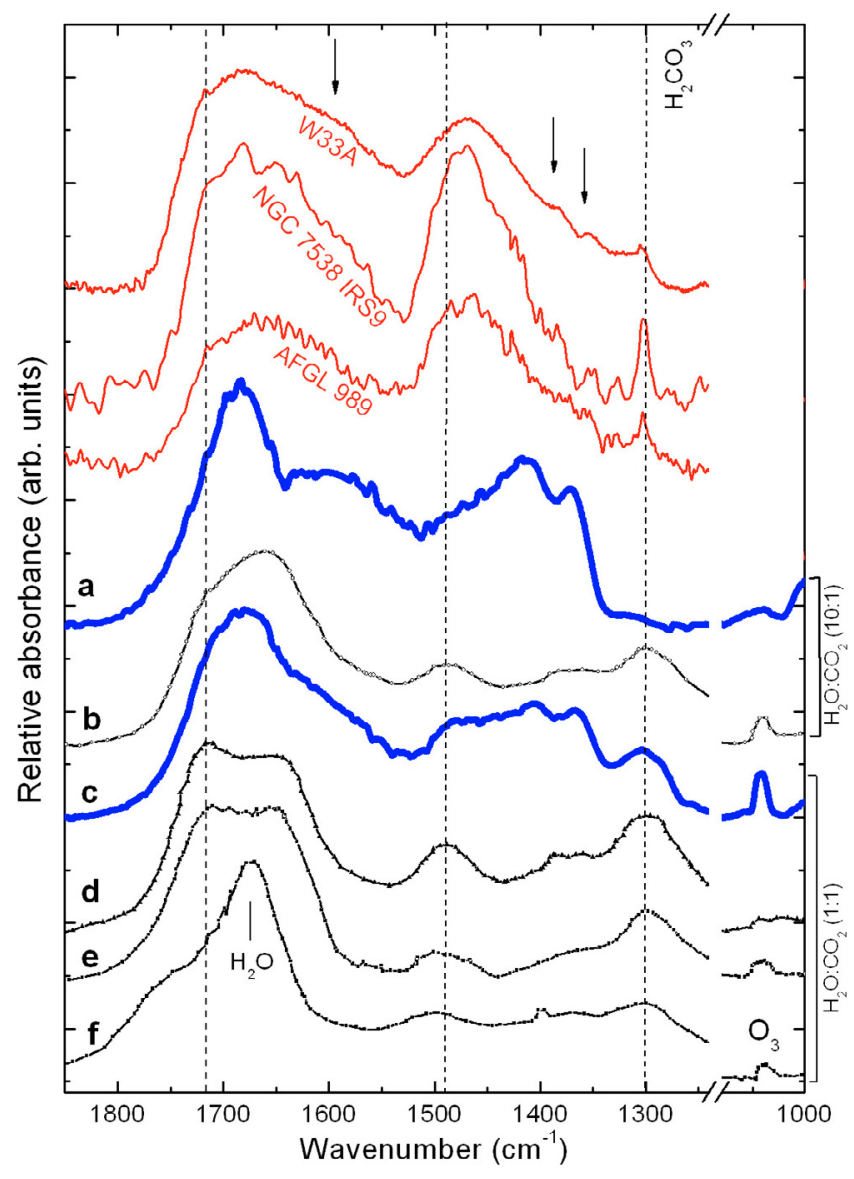

Fig. 9. Comparison between IR spectra of interstellar and laboratory ices. The top three curves are infrared spectra of young stellar sources obtained by the Infrared Space Observatory (ISO). Lower traces indicate different laboratory spectra of irradiated $\mathrm{H}_{2} \mathrm{O}: \mathrm{CO}_{2}$ ices: a) and c) (this work); b) (Hudson \& Moore 2001); d) (Gerakines et al. 2000); e) (Strazzulla et al. 2005b); f) (UV photons, Gerakines et al. 2000). Vertical dashed lines indicate the location of vibrational modes of frozen $\mathrm{H}_{2} \mathrm{CO}_{3}$.

shown in Fig. 9. The IR spectra of young stellar sources (top tree curves) were obtained by the Infrared Space Observatory (ISO). The six bottom curves indicate different laboratory spectra of processed $\mathrm{H}_{2} \mathrm{O}: \mathrm{CO}_{2}$ ices: a) mixture (10:1) irradiated by $52 \mathrm{MeV} \mathrm{Ni}$ ions (this work); b) mixture (10:1) irradiated by $0.8 \mathrm{MeV}$ protons (Hudson \& Moore 2001); c) mixture (1:1) irradiated by $52 \mathrm{MeV}$ Ni ions (this work); d) mixture (1:1) irradiated by $0.8 \mathrm{MeV}$ protons (Gerakines et al. 2000); e) mixture (1:1) irradiated by $0.8 \mathrm{MeV}$ protons (Strazzulla et al. 2005b); and f) mixture (1:1) irradiated by UV photons (Gerakines et al. 2000). Our data are represented by two bold (blue) curves. The location of vibrational modes of frozen $\mathrm{H}_{2} \mathrm{CO}_{3}$ (Moore \& Khanna 1991) is indicated. The presence of $\mathrm{H}_{2} \mathrm{CO}_{3}$ seems to be independent of the ionization source.

The three bumps observed on the IR spectra of the young stelar objects at about $1600 \mathrm{~cm}^{-1}, 1400 \mathrm{~cm}^{-1}$, and $1350 \mathrm{~cm}^{-1}$ (see arrows in Fig 9) present a good similarity with the features present in the IR spectra of $\mathrm{H}_{2} \mathrm{O}: \mathrm{CO}_{2}(10: 1)$ irradiated by $52 \mathrm{MeV}$ ions (curve a). Nevertheless, up to now, its molecular assignment remains unknown. Although very attenuated, these features are still observed in the IR spectra of $\mathrm{H}_{2} \mathrm{O}: \mathrm{CO}_{2}(1: 1)$ (curve c). This suggests that heavy cosmic rays can be good candidates for explaining some features observed in the IR spectra of some interstellar sources. 
The comparison between the current results with the previous one (Pilling et al. 2010) reveals that, independent of ice constitution (involving $\mathrm{H}_{2} \mathrm{O}, \mathrm{CO}_{2}, \mathrm{CO}$, and $\mathrm{NH}_{3}$ ), the dissociation cross section due to heavy and energetic cosmic ray analogs are in the same range, $\sigma_{\mathrm{d}}=1-2 \times 10^{-13} \mathrm{~cm}^{2}$. This supports the extension of our previous estimative for the half-life of ammoniacontaining ice, $\tau_{1 / 2}=2-3 \times 10^{6}$ years, to all kinds of interstellar grains inside dense interstellar environments in the presence of a constant galactic heavy cosmic ray flux.

The temperature of solar system ices is about $80 \mathrm{~K}$, a value about 5-8 times higher than observed in interstellar ices; therefore, some molecular species (the most volatile as $\mathrm{O}_{3}$ and $\mathrm{CO}$ ) are not efficiently trapped/adsorbed in/on the ices. This can make an enormous difference in surface and bulk chemistry. Future experiments employing $\mathrm{H}_{2} \mathrm{O}: \mathrm{CO}_{2}$ ices at $80 \mathrm{~K}$ will be performed to investigate this question.

\section{Summary and conclusions}

The interaction of heavy, highly charged, and energetic ions $\left(52 \mathrm{MeV}{ }^{58} \mathrm{Ni}^{13+}\right.$ ) with pure $\mathrm{H}_{2} \mathrm{O}$ and $\mathrm{CO}_{2}$ ices and mixed $\left(\mathrm{H}_{2} \mathrm{O}: \mathrm{CO}_{2}\right)$ ices was studied experimentally. The aim was to understand the chemical and the physicochemical processes induced by heavy cosmic rays inside dense and cool astrophysical environments, such as molecular clouds and protostellar clouds, as well on the surfaces solar system ices. Our main results and conclusions are the following.

1. In all experiments containing $\mathrm{CO}_{2}$ (pure ice and mixtures) after a fluence of about $2-3 \times 10^{12}$ ions $\mathrm{cm}^{-2}$, the $\mathrm{CO}_{2} / \mathrm{CO}$ ratio became roughly constant $(\sim 0.1)$, independent of initial $\mathrm{CO}_{2} / \mathrm{H}_{2} \mathrm{O}$. The experiments suggest that the abundances of $\mathrm{CO}_{3}, \mathrm{O}_{3}$, and $\mathrm{H}_{2} \mathrm{CO}_{3}$ in typical astrophysical ices $\left(\left[\mathrm{CO}_{2}\right] /\left[\mathrm{H}_{2} \mathrm{O}\right] \sim 0.05-0.1\right)$ irradiated by heavy ions, should be very low, except for those ices with peculiar enrichment of $\mathrm{CO}_{2}$.

2. After a fluence of about $2-3 \times 10^{12}$ ions $\mathrm{cm}^{-2}$, the $\mathrm{H}_{2} \mathrm{O}_{2} / \mathrm{H}_{2} \mathrm{O}$ ratio stabilizes at $\sim 0.01$, is independent of initial $\mathrm{H}_{2} \mathrm{O}$ relative abundance and column density.

3. A comparison between our radiochemical yields and cross sections with the literature have revealed higher values for both the formation and destruction of $\mathrm{H}_{2} \mathrm{O}_{2}$ during bombardments of ices by heavy and energetic ions. In other words, the chemical processing is enhanced by the processing of ices by heavy and energetic and highly charged ions in comparison to light ions.

4. The dissociation cross section of pure $\mathrm{H}_{2} \mathrm{O}$ and $\mathrm{CO}_{2}$ ices are 1.1 and $1.9 \times 10^{-13} \mathrm{~cm}^{2}$, respectively. For mixed $\mathrm{H}_{2} \mathrm{O}: \mathrm{CO}_{2}$ (10:1) ice, the dissociation cross section of both species is roughly $1 \times 10^{-13} \mathrm{~cm}^{2}$.

5. Some IR features observed in ices after the bombardment by heavy ions present a strong similarity with those observed at molecular clouds, suggesting that heavy cosmic rays play an important role in the processing of frozen compounds in interstellar environments.

Acknowledgements. The authors acknowledge the agencies COFECUB (France), CAPES, CNPq, and FAPERJ (Brazil) for financial support. We thank Th. Been, I. Monnet, Y. Ngono-Ravache, and J.M. Ramillon for technical support.

\section{References}

Allamandola, L. J., Bernstein, M. P., Sandford, S. A., \& Walker, R. L. 1999, Space Sci. Rev., 90, 219

Baragiola, R. A., Loeffler, M. J., Raut, U., Vidal, R. A., \& Carlson, R. W. 2004, Lunar and Planetary Science Conference, 35, 2079

Baragiola, R. L. A., Loeffler, M. J., Raut, U., Vidal, R. A., \& Wilson, C. D. 2005, Radiat. Phys. Chem., 72, 187

Bennett, C. J., Jamieson, C. S., Mebel, A. M., \& Kaiser, R. I. 2004, Phys. Chem. Chem. Phys., 6, 735

Bockelée-Morvan, D. 1997, in Molecules in Astrophysics: Probes and Processes, ed. E. F. van Dishoeck (Dordrecht: Kluwer), 218

Boudin, N., Schutte, W. A., \& Greenberg, J. M. 1998, A\&A, 331, 749

Bouwman, J., Ludwig, W., Awad, Z., et al. 2007, A\&A, 476, 995

Brown, W. L., Augustyniak, W. M., Marcantonio, K. J., et al. 1984, Nucl. Instr. and Meth. B1, IV, 307

Brucato, J. R., Palumbo, M. E., \& Strazzulla, G. 1997, Icarus, 125, 135

Carlson, R. W., Anderson, M. S., Johnson, R. E., et al. 1999, Science, 283, 2062

Carlson, R. W., Hand, K. P., Gerakines, P. A., Moore, M. H., \& Hudson, R. L. 2005, BAAS, 37, 5805

Cooper, P. D., Johnson, R. E., \& Quickenden, T. I. 2003, Icarus, 166, 444

Cooper, P. D., Moore, M. H., Hudson, R. L., et al. 2008, Icaurs, 194, 379

Crovisier, J. 1998, Faraday Discuss., 109, 437

Crovisier, J., Leech, K., Bockelee-Morvan, D., et al. 1997, Science, 275, 1904

DelloRusso, N., Khanna, R. K., \& Moore, M. H. 1993, JGR, 98, 5505

Drury, L. O. C., Meyer, J.-P., \& Ellison, D. C. 1999, Topics in Cosmic-Ray Astrophysics, ed. M. A. DuVernois (New-York: Nova Science Publishers)

Ehrenfreund, P., \& Charnley, S. B. 2000, ARA\&A, 38, 427

Elsila, J., Allamandola, L. J., \& Sandford, S. A. 1997, ApJ, 479, 818

Ferrante, R. F., Moore, M. H., Morgan, M., Spiliotis, M. M., \& Hudson, R. L. 2008, ApJ, 684, 1210

Gerakines, P. A., \& Moore, M. H. 2001, Icarus, 154, 372

Gerakines, P. A., Scutte, W. A., Greenberg, J. M., \& van Dishoeck, E. F. 1995, A\&A, 296, 810

Gerakines, P. A., Schutte, W. A., \& Ehrenfreund, P. 1996, A\&A, 312, 289

Gerakines, P. A., Whittet, D. C. B., Ehrenfreund, P., et al. 1999, ApJ, 522, 357

Gerakines, P. A., Moore, M. H., \& Hudson, R. L. 2000, A\&A, 357, 793

Gibb, E. L., Whittet, D. C. B., Schutte, W. A., et al. 2000, ApJ, 536, 347

Gomis, O., Satorre, M. A., Strazzulla, G., \& Leto, G. 2004a, PSS, 52, 371

Gomis, O., Leto, G., \& Strazzulla, G. 2004b, A\&A, 420, 405

Grevesse, N., Noels, A., \& Sauval, J. A. 1996, ASP Conf. Ser., 99, 117

Hage, W., Liedl, K. R., Hallbrucker, A., \& Mayer, E. 1998, Science, 279, 1332

d'Hendecourt, L. B., \& Allamandola, L. J. 1986, A\&AS, 64, 453

Hendrix, A. R., Barth, C. A., Stewart, A. I. F., Hord, C. W., \& Lane, A. L. 1999, LPI, 30, 2043

Herr, K. C., \& Pimentel, G. C. 1969, Science, 166, 496

Hudson, R. L., \& Moore, M. H. 2001, J. Geoph. Res., 106, 33275

Iza, P., Farenzena, L. S., Jalowy, T., Groeneveld, K. O., \& da Silveira, E. F. 2006, Nucl. Instr. Meth. Phys. Res., Sect. B, 245, 61

Johnson, R. E., \& Quickenden, T. I. 1997, JGR, 102, 10985J

Johnson, R. E., Carlson, R. W., Cooper, J. F., et al. 2004, in Jupiter: The planet, satellites and magnetosphere, ed. F. Bagenal, T. E. Dowling, \& W. B. McKinnon, Cambridge Planetary Science, vol. 1 (Cambridge, UK: Cambridge University Press), 485

Khanna, R. K., Tossell, J. A., \& Fox, F. 1994, Icarus, 112, 541

Larson, H. P., \& Fink, U. 1972, ApJ, 171, L91

Leto, G., \& Baratta, G. A. 2003, A\&A, 397, 7

Loeffler, M. J., Barata, G. A., Palumbo, M. E., Strazulla, G., \& Baragiola, R. A. 2005, A\&A, 435, 587

Loeffler, M. J., Raut, U., Vidal, R. A., Baragiola, R. A., \& Carlson, R. W. 2006, Icarus, 180, 265

McCord, T. B., Carlson, R., Smythe, W., et al. 1997, Science, 278, 271

McCord, T. B., Hansen, G. B., Clark, R. N., et al. 1998, J. Geophys. Res., 103, 8603

Moore, M., \& Hudson, R. L. 2000, Icarus, 145, 282

Moore, M. H., \& Khanna, R. K. 1991, Spectrochim. Acta, 47, 255

Mewaldt, R. A., Cohen, C. M. S., Mason, G. M., Haggerty, D. K., \& Desai, M. I. 2007, Space Sci. Rev., 130, 323

Nastasi, M., Mayer, J., \& Hirvonen, J. K. 1996, in Ion-Solid Interactions: Fundamentals and Applications, Cambridge Solid State Science Series (Cambridge University Press)

Noll, K. S., Johnson, R. E., Lane, A. L., Domingue, D. L., \& Weaver, H. A. 1996, Science, 273, 341

Noll, K. S., Roush, T. L., Cruikshank, D. P., Johnson, R. E., \& Pendleton, Y. J. 1997, Nature, 388, 45

Öberg, K. I., Fraser, H. J., Boogert, A. C. A., et al. 2007, A\&A, 462, 1187

Pan, X. N., Bass, A. D., Jay-Gerin, J. P., \& Sanche, L. 2004, Icarus, 172, 521

Palumbo, M. E. 2006, A\&A, 453, 903 
Palumbo, M. E., Baratta, G. A., \& Spinella, F. 2006, Mem. S.A.It. Suppl., 9, 192 Palumbo, M. E., Leto, P., Siringo, C., \& Trigilio, C. 2008, ApJ, 685, 1033

Paul, J. B., Collier, C. P., Saykally, R. J., Scherer, J. J., \& O'Keefe, A. 1997, J. Phys. Chem. A, 101, 5211

Peeters, Z., Hudson, R., \& Moore, M. 2008, DPS, 40, 5405

Pilling, S., Seperuelo Duarte, E., da Silveira, E. F., et al. 2010, A\&A, 509, A87

Quirico, E., Douté, S., Schmitt, B., et al. 1999, Icarus, 139, 159

Reedy, R. C., \& Arnold, J. R. 1972, J. Geophys. Res., 77, 537

Seperuelo Duarte, E., Boduch, P., Rothard, H., et al. 2009, A\&A, 502, 599

Seperuelo Duarte, E., Domaracka, A., Boduch, P., et al. 2010, A\&A, 512, A71

Simpson, J. A. 1983, Ann. Rev. Nucl. Part. Sci., 33, 323

Smith, M. A. H., Rinsland, C. P., Fridovich, B., \& Rao, K. N. 1985, in Molecular Spectroscopy: Modern Research (London: Academic), 3

Strazzullla, G., Brucato, J. R., Cimino, G., \& Palumbo, M. E. 1996, Planet. Space Sci., 44, 1447

Strazzulla, G., Brucato, J. R., Palumbo, M. E., \& Satorre, M. A. 1997, A\&A, 321,618

Strazzulla, G., Leto, G., Gomis, O., \& Satorre, M. A. 2003, Icarus, 164, 163

Strazzulla, G., Leto, G., Spinella, F., \& Gomis, O. 2005a, Astrobiology, 5, 612
Strazzulla, G., Leto, G., Spinella, F., \& Gomis, O. 2005b, Mem. S.A.It. Suppl., 6,51

Teolis, B. D., Shi, J., \& Baragiola, R. A. 2009, JCP, 130, 134704

Wayne, R. P. 1995, Chemistry of the Atmospheres, Chaps. 8 and 9 (Oxford: Clarendon Press)

Westall, F., Gobbi, P., Gerneke, D., \& Mazzotti, G. 1998, in Lunar and Planetary Institute Conference Abstracts, 1362

Whittet, D. C. B., Schutte, W. A., Tielens, A. G. G. M., et al. 1996, A\&A, 315 , L357

Whittet, D. C. B., Gerakines, P. A., Tielens, A. G. G. M., et al. 1998, ApJ, 498, L159

Wu, C. Y. R., et al. 2003, J. Geophys. Res., 108(E4), 13-1

Vaniman, D., Reedy, R., Heiken, G., Olhoeft, G., \& Mendell, W. 1991, in Lunar Sourcebook: a user's guide to the Moon, ed. G. H. Heiken, D. T. Vaniman, \& B. M. French (Cambridge Univ. Press), 55

Zheng, W., \& Kaiser, R. I. 2007, Chem. Phys. Lett., 450, 55

Zheng, W., Jewitt, D., \& Kaiser, R. 2006, ApJ, 639, 534

Ziegler, J. F. 2003, Stopping and Range of Ions in Matter SRIM2003 (available at www.srim.org) 